\title{
Stocks with Extreme Past Returns: Lotteries or Insurance?
}

\author{
Alexander Barinov \\ Terry College of Business \\ UNIVERsity of GeORGIA \\ E-mail: abarinov@terry.uga.edu \\ http://abarinov.myweb.uga.edu/
}

This version: October 2013

\begin{abstract}
The paper shows that lottery-like stocks are hedges against unexpected increases in market volatility. The loading on the aggregate volatility risk factor explains low returns to stocks with high maximum returns in the past (Bali, Cakici, and Whitelaw, 2011) and high expected skewness (Boyer, Mitton, and Vorkink, 2010). Aggregate volatility risk also explains the new evidence that the maximum effect and the skewness effect are stronger for the firms with high short-sale constraints, high market-to-book, and low credit rating.
\end{abstract}

JEL Classification: G11, G12, E44

Keywords: extreme returns, skewness, lottery, idiosyncratic volatility, aggregate volatility risk 


\section{Introduction}

Recent research has established that stocks with lottery-like payoffs, i.e., the ones that offer a small chance of a huge payoff, earn low returns going forward. Boyer, Mitton, and Vorkink (2010) document a negative association between individual firm skewness and future returns, and Bali, Cakici and Whitelaw (2011) establish a similar relation between extreme positive returns in the past month and expected returns in the next month.

The theoretical argument behind the tendency of lottery-like stocks to have low future returns is developed in Barberis and Huang (2008), Brunnermeier and Parker (2005) and Mitton and Vorkink (2007), among others. Mitton and Vorkink introduce in their model "lotto investors" with explicit skewness preference, who bid up the prices of lottery-like stocks. Barberis and Huang develop a model with prospect theory utility and show that the preference for lottery-like stocks arises from the tendency to overestimate the probability of the large gain observed in psychological experiments. Barberis and Huang show that prospect-utility investors value lottery-like stocks higher than expected-utility investors would. Brunnermeier and Parker argue that the overestimation of the probability of rare positive event results from the attempt to choose the optimal set of beliefs to maximize the current felicity. The agents in Brunnermeier and Parker trade off the costs of holding biased beliefs with the gains from believing in what makes them happier. The trade-off results in an internal solution with overvaluation of lottery-like stocks (from the point of view of an investor with unbiased beliefs).

This paper offers a rational explanation of why lottery-like stocks have low expected returns by pointing out that such stocks tend to act as a valuable insurance against unexpected increases in market volatility. Lottery-like stocks tend to be growth stocks with 
high idiosyncratic volatility, and, as Barinov (2011, 2013) shows, such stocks are hedges against aggregate volatility risk. Thus, lottery-like stocks should also be hedges against aggregate volatility risk.

The reason why growth firms with high idiosyncratic volatility, and lottery-like stocks in particular, are hedges against aggregate volatility risk, is two-fold. First, growth options, as any option, react positively to increases in volatility, holding everything else fixed, as Grullon, Lyandres, and Zhdanov (2012) show. As Barinov (2013), Duarte et al. (2012), and Kelly et al. (2013) show, idiosyncratic volatility has a strong common component that comoves significantly with market volatility. Hence, the favorable reaction of growth options to increases in firm-level volatility implies that they will do well when aggregate volatility increases. This effect will naturally be stronger for volatile firms, because such firms tend to see larger absolute increases in firm-level volatility.

Second, as Johnson (2004) proves, higher volatility of the underlying makes the growth option less sensitive to the changes in its value and therefore, less risky. The comovement between firm-level volatility and market volatility adds an interesting twist to it: when market volatility and market risk premium go up, betas of growth options will go down due to an increase in the volatility of the underlying. Thus, growth options will suffer a smaller price drop due to a smaller increase in their risk and discount rate.

The empirical analysis in my paper proceeds as follows. I first show that firms with high extreme returns in the past and firms with high expected idiosyncratic skewness tend to have high idiosyncratic volatility and firm-specific uncertainty, as well as option-like equity, which would be the necessary condition for the aggregate volatility risk explanation.

I then form an aggregate volatility risk factor (FVIX factor) by creating an arbitrage portfolio that would mimic daily changes in the VIX index. VIX is implied volatility of the 
options on S\&P 100, and thus can be used as a measure of expected aggregate volatility. ${ }^{1}$ As Ang, Hodrick, Xing, and Zhang (2006) show, at daily frequency the autocorrelation of VIX is very close to one, therefore, daily change in VIX should be a good proxy for innovations to expected aggregate volatility, the state variable of interest in the ICAPM context.

I find that FVIX is tightly correlated with the VIX change, earns a significant risk premium, and can predict future volatility, as Chen (2002) suggests a valid aggregate volatility risk factor should do.

Most importantly, the FVIX factor can explain the maximum effect of Bali et al. (2011) and the skewness effect of Boyer et al. (2010). The aforementioned effects stand at around 60 bp per month prior to controlling for FVIX, and controlling for FVIX reduces them to almost zero.

The portfolios of lottery-like stocks (with the most positive skewness or the largest maximum/minimum returns) also exhibit large and positive FVIX betas. Since FVIX is, by construction, positively correlated with unexpected changes in aggregate volatility, the positive betas show that lottery-like stocks beat the CAPM when VIX goes up and are therefore hedges against aggregate volatility risk.

My hypothesis is that the aggregate volatility risk explanation of low returns to lotterylike stocks works through convexity in firm value. An obvious prediction is that the skewness effect and the maximum effect should be stronger for growth stocks, and this regularity should be explained by aggregate volatility risk. This is exactly what I find: the maximum effect and skewness effect are by roughly 60 bp per month greater for growth

\footnotetext{
${ }^{1}$ The paper uses the old definition of FVIX, because it has longer coverage, including October 1987. The current VIX uses options on S\&P 500, and the index used in the paper is currently called VXO. All results in the paper are robust to using the newer VIX.
} 
stocks than for value stocks. In the two-factor ICAPM with the market factor and FVIX, this difference is reduced to about $20 \mathrm{bp}$ per month. Also, the ICAPM reveals that growth lottery-like stocks load more positively on FVIX and thus offer a significantly better hedge against aggregate volatility risk than value lottery-like stocks.

By the same token, I predict that the expected returns to lottery-like stocks will be lower and their hedging power against aggregate volatility risk will be greater if the equity of the firm is more option-like due to the existence of risky debt and limited liability. I measure the option-likeness of equity by looking at credit rating: firms with lower credit rating are closer to the point where limited liability starts to matter, and their equity is thus more option-like.

I find that the maximum effect and the skewness effect are indeed stronger for the firms with lower credit rating, and this regularity can be explained by aggregate volatility risk. I also find that lottery-like stocks with low credit rating are better hedges against aggregate volatility risk than lottery-like stocks with high credit rating.

Because the literature on lottery-like stocks currently attributes their low returns to overpricing, I test whether the maximum effect and skewness effect are indeed stronger for firms with binding short-sale constraints. To the best of my knowledge, this test is new to the literature on lottery-like stocks.

I do find that lottery-like stocks tend to be short-sale constrained and that the maximum effect and the skewness effect are indeed stronger by 40-70 bp per month for firms with low institutional ownership and high relative short interest. However, I also find that the relation between the maximum/skewness effect and short-sale constraints disappears once I control for aggregate volatility risk.

The reason why FVIX explains the relation between the maximum effect and short-sale 
constraints is that short-sale constrained stocks tend to have high past maximum returns, and sorting them on the past maximum returns produces a wider spread in maximum returns, which also implies a wider spread in expected returns, firm-specific uncertainty, and aggregate volatility.

I conclude therefore that there is no indication that the low returns to lottery-like stocks arise because of mispricing, but there is clear evidence that lottery-like stocks protect investors against unexpected increases in aggregate volatility and this hedging property explains the maximum effect and skewness effect.

Lastly, I consider the minimum effect, which is supposed to be symmetric to the maximum effect of Bali et al. (2011). If investors have a preference for positive skewness or lottery-like stocks, they will avoid the stocks that have high probability of a disastrous loss. Thus, sorting firms on the past minimum return should reveal that stocks with the most negative past minimum return have the highest expected returns.

However, my explanation of the maximum effect implies the opposite prediction: if the maximum effect exists because past maximum return proxies for idiosyncratic volatility, and idiosyncratic volatility in turn proxies for aggregate volatility risk exposure, past minimum return will pick up the same things and will be negatively related to future returns.

In the data, I find that firms with the most negative past minimum returns earn negative alphas of the same magnitude as the firms with the most positive past maximum returns, consistent with my explanation of the maximum effect and inconsistent with the currently accepted view that the low expected returns to the firms with high maximum returns are due to lottery preference. I also find that the minimum effect is explained by aggregate volatility risk factor, that the minimum effect is stronger for growth firms 
and distressed firms, just as the maximum effect is, and that these regularities can be successfully explained by the FVIX factor. The totality of this evidence strengthens my case that both the maximum and minimum effect capture uncertainty effects and can therefore be explained by aggregate volatility risk.

\section{Data}

The main test assets in the paper are quintile portfolios sorted on three variables of interest: the maximum past return (as in Bali et al., 2012), the expected skewness (as in Boyer et al., 2010), and the minimum past return. The sorts use NYSE (exchcd=1) breakpoints. Stocks with prices below $\$ 5$ on the portfolio formation date are excluded. The results in the paper are robust to using CRSP breakpoints and/or including the stocks priced below $\$ 5$ back into the sample, as in Bali et al. and Boyer et al.

The maximum past return is the maximum daily return in the past month. The minimum past return is defined in the same way, but is multiplied by -1 , so that high values of the minimum return mean "lottery-like" stocks.

Following Boyer et al. (2010), expected skewness is defined as the expected value from

$$
\begin{aligned}
\text { ISkew }_{t}= & \gamma_{0}+\gamma_{1} \cdot \text { ISkew }_{t-60}+\gamma_{2} \text { IVol }_{t-60}+\gamma_{3} \cdot \text { Mom }_{t-60}+\gamma_{4} \cdot \text { Turn }_{t-60}+ \\
& +\gamma_{5} \cdot N A S D_{t-60}+\gamma_{6} \cdot \text { Small }_{t-60}+\gamma_{7} \cdot \text { Med }_{t-60}+\Gamma \cdot \text { IndDum }
\end{aligned}
$$

The regression is performed in cross-section every month. The left-hand side variable is idiosyncratic skewness (ISkew), computed from daily returns in the past 60 months. The right-hand side includes idiosyncratic volatility (IVol), also computed from daily returns in the past 60 months, cumulative monthly return in the past 12 months excluding the most recent one (Mom), average monthly turnover in the past year (Turn), NASDAQ 
dummy (NASD), small firms dummy (Small), medium firms dummy (Med), and industry dummies. Detailed definitions of all variables are in Data Appendix.

To measure the innovations to expected aggregate volatility, I use daily changes in the old version of the VIX index calculated by CBOE and available from WRDS. Using the old version of VIX provides longer coverage. The VIX index measures the implied volatility of the at-the-money options on the S\&P100 index.

I form a factor-mimicking portfolio that tracks the daily changes in the VIX index. I regress the daily changes in VIX on the daily excess returns to the base assets. The base assets are five quintile portfolios sorted on the past return sensitivity to VIX changes, as in Ang et al. (2006):

$$
\begin{aligned}
\Delta V I X_{t}= & \gamma_{0}+\gamma_{1} \cdot\left(V I X 1_{t}-R F_{t}\right)+\gamma_{2} \cdot\left(V I X 2_{t}-R F_{t}\right)+ \\
& +\gamma_{3} \cdot\left(V I X 3_{t}-R F_{t}\right)+\gamma_{4} \cdot\left(V I X 4_{t}-R F_{t}\right)+\gamma_{5} \cdot\left(V I X 5_{t}-R F_{t}\right),
\end{aligned}
$$

where $V I X 1_{t}, \ldots, V I X 5_{t}$ are the VIX sensitivity quintiles described below, with $V I X 1_{t}$ being the quintile with the most negative sensitivity.

The fitted part of the regression above less the constant is my aggregate volatility risk factor (FVIX factor):

$$
\begin{aligned}
F V I X_{t}= & \hat{\gamma_{1}} \cdot\left(V I X 1_{t}-R F_{t}\right)+\hat{\gamma_{2}} \cdot\left(V I X 2_{t}-R F_{t}\right)+\hat{\gamma_{3}} \cdot\left(V I X 3_{t}-R F_{t}\right)+ \\
& +\hat{\gamma_{4}} \cdot\left(V I X 4_{t}-R F_{t}\right)+\hat{\gamma_{5}} \cdot\left(V I X 5_{t}-R F_{t}\right) .
\end{aligned}
$$

The return sensitivity to VIX changes I use to form the base assets is measured separately for each firm-month by regressing daily stock excess returns in the past month on daily market excess returns and the VIX index change using daily data (at least 15 non-missing returns are required):

$$
\operatorname{Ret}_{t}-R F_{t}=\alpha+\beta_{M K T} \cdot\left(M K T_{t}-R F_{t}\right)+\gamma_{\Delta V I X} \cdot \Delta V I X_{t}
$$


In untabulated results, I find that the results in the paper are robust to changing the base assets from the VIX sensitivity quintiles to the ten industry portfolios (Fama and French, 1997) or the six size and book-to-market portfolios (Fama and French, 1993).

\section{Lottery-Like Stocks and Aggregate Volatility Risk}

\subsection{FVIX as an ICAPM Factor}

My aggregate volatility risk explanation of the maximum effect and the skewness effect has two necessary conditions. First, sorting on the maximum past return should also produce a sort on volatility and option-likeness of equity, and thus a sort on the exposure to aggregate volatility risk. Second, the FVIX factor I use to explain the maximum effect should satisfy the three requirements for a valid volatility risk factor: it should be significantly correlated with the variable it mimics, it has to earn a significant risk premium, and, as Chen (2002) shows, its return should predict future volatility.

In Table 1, I test these three latter hypotheses. In the left part of Panel A, I find that the correlation between FVIX and the change in VIX it mimics is quite high at 0.653 , t-statistic 14.9. In the right part of Panel A, I find that the raw return to FVIX stands at $-1.21 \%$ per month, t-statistic -3.44, and the CAPM and Fama-French alphas of FVIX are both at -46 bp per month, t-statistics -3.86 and -3.26 .

The negative risk premium to FVIX is to be expected: by construction, FVIX represents the combination of the base assets with the most positive correlation with the change in VIX, and thus the best available hedge against aggregate volatility risk. The return to FVIX then measures what investors are willing to pay for the insurance against increases in VIX, and large negative numbers indicate that investors care about such insurance.

The negative risk premium of FVIX also means that positive FVIX betas signify a 
hedge against aggregate volatility risk, and vice versa.

Panel B explores the prediction of Chen (2002) that a volatility risk factor should predict future volatility. To that end, I regress logs of several measures of volatility VIX, TARCH(1,1) volatility forecast ${ }^{2}$, and squared daily returns as a measure of realized volatility - on leads and lags of FVIX returns. Panel B reports the slopes of these pairwise regressions, as well as the slope from the probit regression of the NBER recession dummy on leads and lags of FVIX returns. The slopes on the lags measure the ability of FVIX to predict volatility and recessions, the slopes on the leads measure the ability of the volatility measures and the NBER recession dummy to predict FVIX returns.

I find that FVIX can indeed predict future volatility one-two quarters ahead, as a valid volatility risk factor should. I also find that FVIX returns can predict future recessions (up to one year ahead), and that high FVIX returns coincide in time with high expected and realized volatility. As expected under the EMH, neither the volatility measures nor the NBER recession dummy can predict FVIX returns.

\subsection{Extreme Returns, Firm-Level Volatility, and Option-Likeness of Equity}

In Table 2, I test the other necessary condition of my explanation of the maximum effect and the skewness effect: the hypothesis that firms with high maximum returns and high skewness also have higher firm-level volatility/uncertainty and option-like equity.

In Panel A, I look at several measures of firm-specific volatility/uncertainty - idiosyncratic volatility, analyst disagreement, analyst forecast error, and volatility of earnings and cash flows (detailed definitions of the variables are in Data Appendix). I find that all volatility/uncertainty measures increase strongly and monotonically (most of them dou-

\footnotetext{
${ }^{2}$ Please refer to Data Appendix for details about the TARCH( 1,1$)$ model.
} 
ble in magnitude) as one goes from firms with the lowest past maximum returns to firms with the highest past maximum returns (Panel A1) or from firms with the most negative expected skewness to the firms with the most positive expected skewness (Panel A2). The link between lottery-likeness and volatility is most probably purely statistical and stems from the fact that observations in the tail contribute to the variance more, and thus a longer right tail implies a higher variance. The evidence in Panel A is also consistent with the evidence in Lu et al. (2013), who find that large price shocks result in a sharp increase in disagreement that slowly dissipates over the next year.

In Panel B, I look first look at growth option measures: market-to-book (the measure of existing growth options), size (the inverse measure of growth options exercised, as suggested by Berk, Green, and Naik (1999)), the R\&D-to-assets ratio (the speed with which growth options are being created), as well as future sales growth and future investmentto-assets ratio (the speed with which growth options will be exercised in the future). I find that lottery-like stocks (stocks with the highest past maximum return and the most positive expected idiosyncratic skewness) are significantly smaller, invest significantly more in $R \& D$, and have significantly higher future sales growth and future investments. The only variable that delivers a split message is market-to-book, which is positively related to the past maximum return, but negatively related to expected skewness.

I then turn to the measure of option-likeness of equity due to existence of risky debt and limited liability - credit rating and O-score (which proxies for the probability of bankruptcy). Credit rating is coded numerically as $\mathrm{AAA}=1, \mathrm{AA}+=2$, etc., and thus higher numerical credit rating implies distress. I find that lottery-like firms have significantly worse credit rating (roughly BB- vs. BBB + for the least lottery-like firms) and significantly higher probability of bankruptcy. Thus, the option-likeness created by limited 
liability is a more important consideration for lottery-like firms.

Lastly, I turn to the general convexity measure from Grullon et al. (2012) - the slope on the squared earnings surprise ("SUE flex" in the table) from the regression of earnings announcement returns on the earnings surprise and its square. This convexity measure is supposed to capture all kinds of equity option-likeness. Consistent with the rest of Panel B, I find that in the sorts on past maximum returns equity convexity almost doubles and in the sorts on expected idiosyncratic skewness equity convexity more than triples as one goes from the least to the most lottery-like stocks.

I conclude that firms with high values of the maximum daily return in the current month also have option-like equity and high firm-specific uncertainty, which should make them hedges against aggregate volatility risk according to my hypothesis. I find the same about firms with high expected idiosyncratic skewness.

\subsection{Explaining the Maximum Effect and the Skewness Effect}

In Panel A of Table 3, I look at the alphas and FVIX betas of quintile portfolios sorted on maximum daily return in the past month. The first two rows confirm the results of Bali et al. (2011) by revealing that sorting firms on the maximum return produces 60 (42) bp per month differential in value-weighted CAPM (Fama-French) alphas ${ }^{3}$. The alpha differential is driven primarily by large and significant negative alphas of lottery-like stocks.

When I control for aggregate volatility risk by adding FVIX to either the CAPM or Fama-French model, I find that the maximum effect of Bali et al. (2011) is reduced to -11 bp per month and -3 bp per month, respectively. The FVIX betas in both the two-factor

\footnotetext{
${ }^{3}$ The alpha differential is smaller than in Bali et al., because Bali et al. use CRSP, not NYSE, breakpoints, and do not exclude stocks priced below $\$ 5$ at the portfolio formation date.
} 
ICAPM and the four-factor model reveal significant hedging power of lottery-like stocks against aggregate volatility risk, which explains their negative alphas in the CAPM and Fama-French (1993) model.

In Panel B, I look at the alphas and FVIX betas of skewness quintile portfolios. In the top two rows, I find that the skewness effect is $54 \mathrm{bp}(60 \mathrm{bp})$ per month in CAPM (Fama-French) alphas. Similar to the maximum effect, the skewness effect is driven almost exclusively by the negative alphas of firms with the most positive skewness (lottery-like firms).

In the third row, I look at the alphas from the ICAPM with the market factor and FVIX. I find that once aggregate volatility risk is controlled for, the skewness effect completely disappears. The low-minus-high alpha differential is reduced to $-8.2 \mathrm{bp}$ per month, and the alphas of the firms with the most positive skewness become insignificantly positive rather than significantly negative.

In the fourth row, I document the hedging ability of firms with the most positive skewness against aggregate volatility risk (significantly positive FVIX betas) and the exposure of firms with the most negative skewness to such risk.

In the fifth and sixth row, I repeat the same analysis using the four-factor model with the Fama-French factors and FVIX instead of the two-factor ICAPM. The results are largely similar, though the low-minus-high alpha differential and the alphas of firms with the most positive skewness are larger (but still insignificant).

I conclude that lottery-like stocks provide an important hedge against aggregate volatility, and this hedge explains their negative CAPM and Fama-French alphas and largely resolves the maximum effect of Bali et al. (2011) and the skewness effect of Boyer et al. $(2010)$. 


\section{Maximum Effect, Skewness Effect, and Option-Like Equity}

\subsection{Maximum Effect, Skewness Effect, and Growth Options}

The aggregate volatility risk explanation of the maximum effect and skewness effect predicts that firms with lottery-like returns will only be hedges against aggregate volatility risk if they have option-like equity. Hence, I explore two predictions that are new to the literature: that the maximum effect and skewness effect are stronger for growth firms and that this regularity is explained by aggregate volatility risk.

In Panel A1 of Table 4, I look at the returns to the low-minus-high portfolio that buys/shorts firms from the quintile with the smallest/largest maximum past returns. This portfolio is formed separately within each market-to-book group. I use three groups firms in the top $30 \%$ in terms of market-to-book (growth firms), firms with market-tobook between the 30th and 70th percentile (neutral firms), and firms with market-to-book in the bottom $30 \%$ (value firms). Panel A reports the CAPM and ICAPM alphas, as well as FVIX betas, of such arbitrage portfolios for each market-to-book group.

In the top row of Panel A1, I report the CAPM alphas and find that the maximum return is significantly stronger (by 61.6 bp per month) for growth firms than for value firms. This pattern is consistent with the aggregate volatility risk explanation of the maximum effect.

In the next row of Panel A1, I control for the FVIX factor and find that the relation between the maximum effect and market-to-book is gone, just as my explanation of the maximum effect predicts. The difference in the ICAPM alphas of the low-minus-high maximum portfolio between value and growth firms is only 16 bp per month, and the maximum effect in the ICAPM alphas is insignificant even for growth firms (for which it 
was at $1.1 \%$ in the CAPM alphas).

Also consistent with my hypothesis, the negative FVIX beta of the low-minus-high maximum portfolio is smaller if the low-minus-high portfolio is formed using only value firms and significantly more negative if the portfolio is formed using only growth firms, revealing that the stronger maximum effect for growth firms comes at the cost of suffering worse losses in response to unexpected increases in aggregate volatility.

In Panel A2, I repeat the analysis for the skewness effect by looking at the alphas and FVIX betas of a low-minus-high arbitrage portfolio that buys/shorts firms with the most negative/positive skewness formed separately in each market-to-book group.

In the first row of Panel A2, I find that the skewness effect indeed exists only for growth firms. I also find that the skewness effect is by $57.7 \mathrm{bp}$ per month stronger for growth firms than for value firms.

In the second row, I find that the skewness effect for growth firms is reduced to $-0.4 \mathrm{bp}$ per month after I control for FVIX. Similarly, the difference in the skewness effect between value and growth firms declines in the ICAPM alphas to 24 bp per month, statistically insignificant.

In the third row, I look at FVIX betas from the same two-factor ICAPM and find that the low-minus-high portfolio that buys/shorts the bottom/top skewness quintile indeed demonstrates more negative FVIX betas in the growth subsample. In untabulated results, I find that the more negative FVIX betas are caused by higher hedging ability of positive skewness (lottery-like) firms in the growth subsample. Positive skewness firms have positive FVIX betas, and shorting them makes the FVIX beta of the low-minus-high portfolio negative. 


\subsection{Maximum Effect, Skewness Effect, and Equity as a Call Op- tion on the Assets}

Another channel through which the aggregate volatility risk explanation of the maximum and skewness effects can work is the option-likeness of equity caused by the existence of risky debt and limited liability. If the firm is close to bankruptcy, its equity is essentially a call option on the assets with the strike price equal to the amount of debt. The aggregate volatility risk story can be retold for this call option: if idiosyncratic volatility of the assets and aggregate volatility both increase, the value of the option (the equity) will increase and its beta will decrease, holding everything else fixed. Thus, the equity will become a hedge against aggregate volatility risk, and more so if the idiosyncratic volatility of the assets is high, as is the case for lottery-like firms (see Table 2), and credit rating is low (because for firms with good credit rating the option-likeness of equity is not an important concern - this option is too deeply in the money).

I make therefore two new predictions: the maximum effect and skewness effect will be stronger for the firms with low credit rating and this regularity will be explained by aggregate volatility risk.

I test this hypothesis in Panel B of Table 4, in which Panel B1 (B2) looks at the relation between the maximum (skewness) effect and credit rating. As in Table 4, I form arbitrage portfolios that buy firms from the quintile with the least lottery-like returns and short firms from the quintile with the most lottery-like returns, separately within each credit rating group. The credit rating groups are the same as the market-to-book groups in Panel A: best $30 \%$, middle $40 \%$, and worst $30 \%$.

In the first row, which reports the CAPM alphas, I find that both the maximum effect and skewness effect are small and insignificant in the best credit rating group, marginally 
significant in the group with intermediate credit rating, and large (up to $1.2 \%$ per month) in the lowest credit rating group. The difference in the maximum/skewness effect between firms with the best and worst credit rating is $111 \mathrm{bp} / 81 \mathrm{bp}$ per month.

When I look at the alphas from the ICAPM with the market factor and FVIX, I find no evidence that, controlling for FVIX, the maximum effect or skewness effect are related to credit rating, which suggests that aggregate volatility risk is the explanation for this relation in the CAPM alphas. Even more impressive, the ICAPM alphas of the low-minus-high maximum portfolio in the worst credit rating group are within 12 bp of zero, as compared with the CAPM alphas that were at $120 \mathrm{bp}$ and $97 \mathrm{bp}$ per month.

The FVIX betas of the low-minus-high portfolio become more negative, very strongly and monotonically, as one goes from the best credit rating group to worst credit rating group. This pattern in FVIX betas confirms that the stronger maximum/skewness effect for low credit rating firms arises because in this subsample, the low-minus-high portfolio tends to suffer worse losses during periods of increasing aggregate volatility due to shorting option-like equity with high firm-specific volatility/uncertainty, since such equity provides the best hedge against aggregate volatility risk.

\section{Mispricing Explanations of the Maximum/Minimum Effects and Aggregate Volatility Risk}

\subsection{Hypotheses Development}

Currently, the literature interprets the low returns to lottery-like stocks as the evidence that these stocks are overpriced. Most theories of why the overpricing exists (e.g., Brunnermeier and Parker, 2005, Barberis and Huang, 2008) argue that investors overestimate the probability of the big win on lottery-like stocks. 
As Barberis and Huang point out in their Section III.F, if lottery-like stocks are overpriced (by investors with prospect theory utility), expected-utility arbitrageurs should be shorting them in an effort to make money on the mispricing and thereby eliminate it. If the mispricing does not disappear, there have to be short-sale constraints that preclude the shorting. Hence, the so far untested implication of the current theory of low returns to lottery-like stocks is that these returns should be even lower, and the maximum and skewness effects should be even stronger, for short-sale constrained firms. ${ }^{4}$

My explanation of the maximum and skewness effect does not exclude the possibility that the maximum and skewness effects, and returns to lottery-like stocks in general, are related to measures of short-sale constraints. However, under my hypothesis, any such relation should be explained by the FVIX factor.

In this section, I use two measures of short-sale constraints: residual institutional ownership (IO) and relative short interest (RSI). As Asquith, Pattak, and Ritter (2005) argue, IO is a proxy for demand for shorting and RSI is a proxy for supply of shares for shorting. Hence, costs of shorting, which are the ultimate variable the proxies are hunting for, should be stronger if IO is low or RSI is high. Since raw IO is strongly related to size, I orthogonalize IO to size following Nagel (2005) and use residual IO instead (see Data Appendix for more details).

If the maximum and skewness effects are mispricing, I expect to see stronger maximum/skewness effect for low IO firms and high RSI firms in both CAPM and ICAPM alphas. If the maximum and skewness effects are explained by aggregate volatility risk, I expect that the relation between the maximum/skewness effect and IO/RSI will not exist

\footnotetext{
${ }^{4} \mathrm{~A}$ recent working paper by Lu et al. (2013) shows that stocks that have experienced extreme price shocks (a measure similar to the maximum daily returns in Bali et al. (2011) have more negative future CARs if they have low institutional ownership, which is somewhat similar to the evidence I present in the top row of Panel C1, Table 5.
} 
in the ICAPM alphas, even if exists in the CAPM alphas.

\subsection{Lottery Likeness and Short-Sale Constraints}

In Panels $\mathrm{A}$ and $\mathrm{B}$ of Table 5, I explore whether stocks with large past maximum returns and high expected idiosyncratic skewness are indeed short-sale constrained. I use four measures of short-sale constraints: IO and RSI, discussed above, estimated shorting fee (Fee) from Boehme, Danielsen, and Sorescu (2006), and estimated probability to be on special (Prob) from Ali and Trombley (2006). Detailed definitions of the variables are in Data Appendix.

In Panel A, I look at quintile sorts on past maximum return and find that firms with high maximum returns are indeed short-sale constrained. Compared to firms with low maximum returns, their median IO is lower by $2 \%$ of shares outstanding (or $11 \%$ of the median IO for firms low maximum return) and their RSI is higher by $0.3 \%$ of shares outstanding (or $141 \%$ of the median RSI for firms low maximum return). The median estimated shorting fee (in percent per year) is also significantly higher for firms with high maximum returns, and the estimated probability to be on special is twice higher for firms with high maximum returns than for firms with low maximum returns.

The fact that firms with extreme past maximum returns are short-sale constrained is consistent with the mispricing explanation of the maximum effect. Yet, the same fact can also explain why the maximum effect will be stronger for short-sale constrained firms even if the maximum effect is explained by aggregate volatility risk. If firms with high maximum returns are short-sale constrained, and vice versa, short-sale constrained firms have, on average, higher maximum returns, sorting on past maximum returns in the subsample of short-sale constrained firms will produce a wider spread in maximum returns and, 
presumably, in aggregate volatility risk.

In Panel B, I consider the sorts on expected skewness and find that, contrary to the expectations in the literature, positive skewness firms are not short-sale constrained. They have significantly higher IO, much lower RSI, and significantly lower estimated shorting fees. The only variable that suggests that firms with highly positive total skewness might be at times difficult to short is the estimated probability to be on special, which increases with total skewness.

Overall, the results in Panel B cast doubt on the view that firms with high expected skewness are overpriced and the overpricing persists because of short-sale constraints. Yet, the lack of association between skewness and short-sale constraints does not harm my explanation of the skewness effect, because firms do not have to be short-sale constrained to be a hedge against aggregate volatility risk.

\subsection{Maximum/Skewness Effects and Institutional Ownership}

In Panel C of Table 5, I look at the performance of the low-minus-high portfolio across residual IO groups (top 30\%, medium 40\%, bottom 30\%). Similar to Table 4, the lowminus-high portfolio buys firms in the lowest maximum/skewness quintile and shorts firms in the highest maximum/skewness quintile, separately for each residual IO group.

In Panel C1, I look at the maximum effect and find that in the CAPM alphas, it is by 48 bp per month stronger in the low IO subsample than in the high IO subsample. In the ICAPM alphas, the difference in the maximum effect between low and high IO firms is reduced to $29 \mathrm{bp}$ per month, t-statistic 1.42. The ICAPM alpha of the low-minus-high portfolio in the low IO group is 25 bp per month, t-statistic 1.13, as compared to its CAPM alpha of 95.4 bp per month, t-statistic 3.3. Overall, I conclude that the relation between 
the maximum effect and IO is more consistent with my explanation than with the view that the maximum effect is mispricing.

Panel $\mathrm{C} 2$ looks at the relation between IO and the skewness effect. I find that the skewness effect is indeed visible only for low IO firms and that the difference in the skewness effect between low and high IO firms is $43 \mathrm{bp}$ per month. This evidence is new to the literature and is consistent with the mispricing explanation of the skewness effect.

The rest of Panel $\mathrm{C} 2$ favors the aggregate volatility risk explanation of the skewness effect. When I look at the ICAPM alphas in the second row, I find no skewness effect for low IO firms and no significant difference in the skewness effect between low IO and high IO firms. I conclude that the relation between IO and the skewness effect is explained by aggregate volatility risk. Consistent with that, I find that the FVIX betas of the low-minus-high portfolio become visibly more negative as I go from high IO to low IO firms.

\subsection{Maximum/Skewness Effects and Relative Short Interest}

In Panel D of Table 5, I consider the CAPM and ICAPM alphas, as well as FVIX betas, of the same low-minus-high portfolios across RSI groups (top 30\%, medium 40\%, bottom 30\%). In Panel D1, I look at the maximum effect and find that the CAPM alphas of the low-minus-high portfolio monotonically increase by 63 bp per month, t-statistic 2.35, from low RSI firms to high RSI firms. This evidence seems consistent with the mispricing explanation of the maximum effect.

However, controlling for FVIX eliminates the relation between the maximum effect and RSI, consistent with my explanation of the maximum effect and inconsistent with the mispricing explanation. The difference between high and low RSI firms in the ICAPM alphas 
of the low-minus-high portfolios is 22 bp per month, t-statistic 0.89 , and the ICAPM alpha of the low-minus-high portfolio in the high RSI subsample is only 24 bp per month, compared to the CAPM alpha of 94.8 bp per month. The FVIX betas also reveal that buying low and shorting high maximum firms means significantly higher exposure to aggregate volatility risk if done in the high RSI subsample.

In Panel D2, I consider the relation between the skewness effect and RSI. I do find in the CAPM alphas that the skewness effect exists only for high RSI firms, for which it is 40.5 bp per month stronger than for low RSI firms (the difference is statistically significant). This evidence is new to the literature and seems to support the mispricing explanation.

In the ICAPM alphas though I observe no skewness effect in all RSI groups and no significant difference in the skewness effect between low and high RSI groups. I also find that trading on the skewness effect in the high RSI subsample would expose the investor to more aggregate volatility risk than trading on the skewness effect in the low RSI subsample, which appears to be the cause of the stronger skewness effect for high RSI firms in the CAPM alphas.

To sum up, in this section I find new evidence that the maximum/skewness effect is stronger for short-sale constrained firms, which would be consistent with their mispricing explanations. However, the rest of the evidence is inconsistent with the mispricing explanation, but is consistent with my aggregate volatility risk explanation. I find that the relation between the maximum/skewness effect and short-sale constraints disappears after I control for FVIX. I conclude that lottery-like stocks (in particular, stocks with highly positive skewness) earn low expected returns because they are good hedges against aggregate volatility risk, not because investors chase lottery-like payoffs and overprice such 
stocks.

\section{Minimum Effect: The Discriminating Test}

In this section, I present the discriminating test between the lottery preference explanation and the aggregate volatility risk explanation. The discriminating test does not rely on the FVIX factor. If investors have a taste for lottery-like stocks (or positive skewness in general), they should also demonstrate the aversion to stocks with long left tails, which are exactly opposite to lotteries. That is, if I sort firms on the minimum daily returns in the past month, I should observe the minimum effect that is the mirror image of the maximum effect: firms with the most negative past minimum returns should have the highest expected returns.

Under my hypothesis, though, the reason why lottery-like stocks earn low future returns is that they are volatile and therefore load positively on FVIX. If volatility, not lotterylikeness, is the main variable, then stocks with large minimum returns should earn low returns as well, because they are just as volatile as stocks with high maximum returns.

Table 6 repeats Table 2 for quintile sorts on the past minimum return and reports median values of firm-specific uncertainty measures and option-likeness measures across the minimum quintiles. For the ease of comparison with the maximum effect, the minimum returns are multiplied by -1 , so that the high minimum return quintile is actually the quintile with the most negative past minimum returns.

Similar to Table 2, Table 6 shows that firms with the most negative past minimum returns ("disaster stocks") are just like the firms with the most positive maximum returns ("lottery stocks"): they are high uncertainty, option-like firms. All measures of uncertainty and option-likeness demonstrate sizeable and statistically significant differences between 
firms with the least and most negative past minimum returns.

In the first two rows of Panel A in Table 7, I report the CAPM and Fama-French alphas across the minimum quintiles. I find that the minimum effect is just as strong as the maximum effect. The differential in CAPM (Fama-French) alphas between firms with the most and least negative minimum returns is 57 (45) bp per month, both highly significant. Also, the minimum effect is driven primarily by the large negative alphas of the "disaster stocks". Hence, it seems that investors not only go for lotteries, but also court disaster, overpaying for the stocks with the highest chance of a huge loss. This is inconsistent with the lottery/skewness preference, but consistent with my explanation that argues that it is volatility, not lottery-likeness that matters.

I further find in Panel A of Table 7 that FVIX factor successfully explains the minimum effect, bringing it to -14 bp per month in the ICAPM with the market factor and FVIX and to 1 bp per month in the four-factor model with the three Fama-French factors and FVIX. Similarly, the large negative alphas of the "disaster stocks" are reduced from south of $-40 \mathrm{bp}$ per month to at most -14 bp per month after controlling for FVIX.

I also find that FVIX betas increase significantly and monotonically across the minimum return quintiles and reach significantly positive values for the "disaster stocks", indicating that such stocks are a hedge against aggregate volatility risk, as predicted by my hypothesis.

In untabulated results, I consider the possibility that the past maximum and minimum returns are closely related, and "lottery firms" are most likely to be, at the same time, "disaster firms". If this is the case, the maximum effect and the minimum effect can be mechanically related. That does not bode well for the prior explanations of the maximum effect, since an investor with a preference for positive skewness or a taste for lotteries 
will not regard highly "lottery stocks" if they are also often "disaster stocks" by another metric. However, I want to be as conservative as possible and look at the minimum effect net of the maximum effect by making the sorts on the past minimum returns conditional on the past maximum returns. I find that even holding the maximum return constant, firms with more negative minimum return earn significantly lower returns, and these low returns are explained by their FVIX exposures.

In Panel $\mathrm{B}$ of Table 7, I repeat Table 4 by looking at the minimum effect across market-to-book and credit rating groups. The results are very similar to Table 4: the minimum effect is virtually absent for value firms and by 80 bp per month stronger for growth firms, but controlling for FVIX largely explains this pattern. FVIX betas also reveal that buying firms with the least and shorting firms with the most negative past minimum returns exposes the investor to greater aggregate volatility risk if performed in the growth subsample. Likewise, the minimum effect is zero for good credit firms and it is by full 96.5 bp per month stronger for option-like distressed firms, but controlling for FVIX eliminates this pattern too.

The existence of the minimum effect and the evidence that it behaves the same way as the maximum effect (goes away after controlling for FVIX, becomes stronger for optionlike firms) is a strong evidence that the low returns to lottery-like stocks are due to their higher idiosyncratic volatility and hence lower aggregate volatility risk, not to a preference for lotteries. In the world with preference for lotteries, "disaster stocks" should have higher, not lower returns, whereas under the volatility risk explanation, maximum and minimum returns should affect future returns in the same way, since both just substitute for individual stock volatility/uncertainty. 


\section{$7 \quad$ Alternative Volatility Risk Factors}

Several recent papers have suggested alternative ways of measuring volatility risk. While simple estimates of innovations to market volatility appear not to be priced, Adrian and Rosenberg (2008) suggest estimating a Component GARCH (C-GARCH) model for market volatility. C-GARCH model, described in detail in Data Appendix, assumes that market volatility has two components, the short-run one, the shocks to which quickly die out, and the long-run one, with extremely persistent shocks. Adrian and Rosenberg (2008) show that both components of market volatility are priced and the three-factor ICAPM with the market factor and the two innovations has better fit than alternative asset-pricing models.

Chen and Petkova (2012) follow a different route and argue that innovations to market volatility appear not to be priced because the true state variable is average total volatility, not market volatility. ${ }^{5}$ Chen and Petkova disaggregate market volatility into average total volatility and average correlation between individual stocks and show that average total volatility is priced and average correlation is not. Chen and Petkova also show that the average volatility factor helps to explain the idiosyncratic volatility discount of Ang et al. (2006), which is, according to my argument in this paper and the evidence in Bali et al. (2011), a close relative of the maximum and skewness effects.

In this section, I test the ability of the alternative volatility risk factors above to explain the maximum, minimum, and skewness effects. For comparison, I also look at two closely related effects: the idiosyncratic volatility discount of Ang et al. (2006) and the analyst disagreement effect of Diether et al. (2002). In Table 8, I compare the performance of

\footnotetext{
${ }^{5}$ Average total volatility is the average total (systematic and non-systematic) volatility of all individual stocks.
} 
five models: the two-factor ICAPM with FVIX, the three-factor ICAPM of Adrian and Rosenberg (2008), the two-factor ICAPM with the average volatility factor, motivated by Chen and Petkova (2012), the four-factor ICAPM with the market factor, the two Adrian and Rosenberg factors, and FVIX, and the three factor ICAPM with the market factor, the average volatility factor, and FVIX.

In Panel A, I look at the alphas of five arbitrage portfolios. Max (Min) is the portfolio that buys firms with the least positive (negative) daily maximum (minimum) returns in the past month and shorts firms with the most positive (negative) maximum (minimum) returns. Skew is the portfolio that buys firms with the most negative and short firms with the most positive expected idiosyncratic skewness. IVol (Disp) is the portfolio that buys firms with the lowest idiosyncratic volatility (analyst forecast dispersion) and shorts firms with the highest idiosyncratic volatility (analyst forecast dispersion).

Column zero of Panel A presents CAPM alphas and confirms the results of Bali et al. (2011), Boyer et al. (2010), Ang et al. (2006), Diether et al. (2002), as well as the existence of the minimum effect discovered in this paper. Column one reports the alphas from the ICAPM with the market factor and FVIX (the baseline model in this paper) and finds that this model completely explains all five effects, consistent with the analysis above and the results in Barinov (2011) on the idiosyncratic volatility discount and in Barinov (2013) on the analyst disagreement effect. $^{6}$

In column two, I look at the alphas from the Adrian and Rosenberg (2008) ICAPM with

\footnotetext{
${ }^{6}$ As Barinov (2011) points out, Ang et al. (2006) arrive at a different conclusion about the ability of FVIX to explain the idiosyncratic volatility discount. The two main reasons is, first, that they only make the sorts on idiosyncratic volatility conditional on FVIX beta instead of running a more powerful test and estimating the ICAPM alphas of low- and high-volatility firms, and, second, that Ang et al. perform the factor-mimicking regression that produces FVIX separately in each month, estimating 6 parameters on 22 observations, which leads to a noisy FVIX, while Barinov (2011), as well as this paper, uses a full-sample factor-mimicking regression, which is a more conventional approach since Breeden et al. (1989).
} 
the market factor and the two factor-mimicking portfolios for the innovations to short-run and long-run volatility (the factor-mimicking procedure is similar to the one used to create FVIX and is described in detail in the Data Appendix). I observe that the short-run and long-run volatility factors help explain about 25-30 bp per month of all effects, but the ICAPM alphas remain economically large and statistically marginally significant. In the column four, I add FVIX to the Adrian and Rosenberg model and witness the alphas to decrease to zero.

I conclude that while Adrian and Rosenberg volatility risk factors largely confirm the main idea of this paper that the maximum, minimum, and skewness effects are explained by volatility risk, the FVIX factor used in this paper is more powerful. This is probably not surprising, since FVIX mimics innovations to implied volatility of options on the market index, thus summarizing all information the market has about future volatility, including the information not available to the econometrician or not used in the C-GARCH model, which looks only at market returns and past market volatility.

In the column three, I look at the alphas from the ICAPM with the market factor and the factor-mimicking portfolio for the innovations to average volatility. ${ }^{7}$ Somewhat unexpectedly, I find that the average volatility factor has virtually no ability to explain any of the effects in the table, including the idiosyncratic volatility discount, which was the focus of Chen and Petkova (2012). In the column five, I also find that there is virtually no overlap between FVIX and the average volatility factor.

The cause of the difference between my Table 8 and Chen and Petkova (2012) is the absence of the innovations to average correlation in my analysis. Chen and Petkova use average correlation as a factor despite their finding that it is not priced. They also use

\footnotetext{
${ }^{7}$ I thank Ralitsa Petkova for sharing the innovation series.
} 
average correlation to create the base assets for the factor-mimicking portfolio that tracks innovations to average volatility. While I use, as base assets, quintile portfolios sorted on past sensitivity to innovations in average volatility, Chen and Petkova use, as base assets, five-by-five quintile sorts on past sensitivity to average volatility and average correlation. As a result, their factor-mimicking portfolio for innovations to average volatility has the factor risk premium of -63 bp per month, while my version of their average volatility risk factor has the factor risk premium of -15 bp per month (still statistically significant). The strong dependence of the average volatility factor of Chen and Petkova on the unpriced characteristic - average correlation - is surprising and suggests that probably average volatility is not the state variable behind market volatility.

In Panels B and C, I look at the volatility risk betas from the five models described above. Panel B deals with non-traded volatility factors (raw innovations to the state variables) from Adrian and Rosenberg (2008) and Chen and Petkova (2012), and Panel C uses the factor-mimicking portfolios used by Panel A.

I reach the following four conclusions. First, the arbitrage portfolios in Table 8 load negatively and significantly on the short-run volatility innovation, but insignificantly on the long-run volatility innovation. Second, FVIX has significant overlap with the short-run volatility factor: in Panel B, FVIX betas stay the same after controlling for the non-traded short-run volatility factor (Model 1 vs. Model 4), but the short-run volatility betas decline by a factor of two and lose significance in the presence of FVIX (Model 2 vs. Model 4). In Panel C, both FVIX betas and short-run volatility betas decline, but remain significant in the presence of the other factor, with FVIX betas suffering a stronger decline (probably responsible for the fact that in Panel A the two-factor ICAPM with the market factor and FVIX (Model 1) explains a bigger part of all anomalies than the four-factor model with 
the market factor, FVIX, and the long-run and short-run volatility factors (Model 4)).

Third, I find that while most arbitrage portfolios load negatively on the average volatility factor of Chen and Petkova, the loading is always insignificant. This is consistent with Panel A, which shows that the average volatility factor contributes only slightly to explaining the anomalies in Table 8. Fourth, I find that FVIX does not overlap with the non-traded average volatility factor in Panel B and slightly overlaps with the traded average volatility factor in Panel C, with FVIX betas intact (Model 1 vs. Model 5) and the average volatility betas visibly declining (Model 3 vs. Model 5) when both factors are used together.

To sum up, I find that in the terms of Adrian and Rosenberg (2008), FVIX captures the short-run volatility risk. This is probably not surprising, since VIX, by definition, is the market volatility forecast for the next month. I also find that FVIX is more powerful than the short-run volatility factor in terms of explaining the anomalies in this paper and related anomalies. The long-run volatility risk does not seem to contribute to explaining the maximum or skewness effects, nor does it intersect with FVIX. That also suggests that my evidence that option-like firms with high uncertainty (which are also seemingly lotterylike) are hedges against volatility risk is complimentary to related evidence in Campbell et al. (2013) that growth firms are hedges against increases in long-run volatility.

As for the average volatility factor of Chen and Petkova (2012), I find that the explanatory power of this factor depends on whether one uses a non-priced state variable - average correlation - for constructing the factor-mimicking portfolio for innovations in average volatility and whether one uses the same non-priced state variable in factor models that include the average volatility factor. If one does not use average correlation along with average volatility, the average volatility factor loses nearly all its explanatory power. 


\section{Conclusion}

The paper presents evidence that lottery-like stocks (stocks with high positive skewness or large daily maximum return in the previous month) earn low expected returns because they are a hedge against increases in aggregate volatility. I find that lottery-like stocks have positive FVIX betas and therefore outperform the CAPM prediction when VIX unexpectedly goes up (FVIX is an aggregate volatility risk factor positively correlated with VIX changes). I also find that controlling for FVIX wipes away two anomalies usually attributed to the alleged overpricing of lottery-like stocks: the maximum effect of Bali, Cakici, and Whitelaw (2011) and the skewness effect of Boyer, Mitton, and Vorkink $(2010)$.

The intuition behind my explanation of low expected returns to lottery-like stocks is that lottery-like stocks are typically volatile stocks with option-like equity, and such stocks are a hedge against aggregate volatility risk, as Barinov (2011, 2013) finds. In preliminary tests, I find that firms with highly positive skewness or large past maximum return indeed have higher firm-specific volatility/uncertainty, more growth options and more convex equity values.

I also successfully test several new hypotheses about cross-sectional behavior of the maximum effect and skewness effect. I find that both the maximum effect and skewness effect are stronger for firms with more option-like equity: firms with high market-to-book or low credit rating. This evidence is consistent with my hypothesis that lottery-like stocks are a hedge against aggregate volatility risk because their equity is option-like. I also find that the link between the maximum/skewness effect, on one hand, and market-to-book and credit rating, on the other, disappears after I control for FVIX, further confirming 
my main hypothesis that the maximum effect and skewness effect stem from the fact that lottery-like stocks are hedges against aggregate volatility risk.

I find new empirical evidence that the maximum effect and skewness effect are stronger for short-sale constrained firms, as the mispricing explanations of those effects would predict. However, the link seems to be largely mechanical and stems primarily from the fact that short-sale constrained stocks are, on average, more lottery-like, and therefore sorting them on lottery-likeness produces a larger spread in lottery-likeness, idiosyncratic volatility, and aggregate volatility risk. Consistent with that, I find that the link between short-sale constraints and the maximum/skewness effect is explained by aggregate volatility risk.

Another new evidence consistent with my explanation of the maximum effect, but inconsistent with the behavioral theories of low returns to lottery-like stocks is the existence of the minimum effect, which behaves just like the maximum effect and is explained by aggregate volatility risk. The minimum effect refers to the fact that firms with the most negative past minimum returns earn the lowest future returns. Its existence is consistent with my idea that extreme (maximum/minimum) past returns proxy for volatility, but not with the existing explanation of the maximum effect - firms with the most negative past minimum returns are exactly opposite of lottery-like. 


\section{References}

[1] Adrian, Tobias, and Joshua Rosenberg, 2008, Stock Returns and Volatility: Pricing the Short-Run and Long-Run Components of Market Risk, Journal of Finance 63, 2997-3030.

[2] Ali, Ashiq, and Mark A. Trombley, 2006, Short Sales Constraints and Momentum in Stock Returns, Journal of Business Finance and Accounting 33, 587-615.

[3] Ang, Andrew, Robert J. Hodrick, Yuhang Xing, and Xiaoyan Zhang, 2006, The CrossSection of Volatility and Expected Returns, Journal of Finance 61, 259-299.

[4] Asquith, Paul, Parag A. Pathak, and Jay R. Ritter, 2005, Short Interest, Institutional Ownership, and Stock Returns, Journal of Financial Economics 78, 243-276

[5] Bali, Turan, Nusret Cakici, and Robert Whitelaw, 2011, Maxing Out: Stocks as Lotteries and the Cross-Section of Expected Returns, Journal of Financial Economics, 99, $427-446$.

[6] Barberis, Nicholas, and Ming Huang, 2008, Stocks as Lotteries: The Implications of Probability Weighting for Security Prices, American Economic Review 98, 2066-2100.

[7] Barinov, Alexander, 2011, Idiosyncratic Volatility, Growth Options, and the CrossSection of Returns, Working paper.

[8] Barinov, Alexander, 2013, Analyst Disagreement and Aggregate Volatility Risk, Journal of Financial and Quantitative Analysis, forthcoming

[9] Berk, Jonathan B., Richard C. Green, and Vasant Naik, 1999, Optimal Investment, Growth Options, and Equity Returns, Journal of Finance 54, 1553-1607. 
[10] Boehme, Rodney D., Bartley R. Danielsen, and Sorin M. Sorescu, 2006, Short Sale Constraints, Differences of Opinion, and Overvaluation, Journal of Financial and Quantitative Analysis 41, 455-488.

[11] Boyer, Brian H., Todd Mitton, and Keith Vorkink, 2010, Expected Idiosyncratic Skewness, Review of Financial Studies 23, 169-202.

[12] Breeden, Douglas T., Michael R. Gibbons, and Robert H. Litzenberger, 1989, Empirical Test of the Consumption-Oriented CAPM, Journal of Finance 44, 231-262.

[13] Brunnermeier, Markus K., and Jonathan A. Parker, 2005, Optimal Expectations, American Economic Review 95, 1092-1118.

[14] Campbell, John Y., Stefano Giglio, Christopher Polk, and Robert Turley, 2013, An Intertemporal CAPM with Stochastic Volatility, Working paper.

[15] Chen, Joseph, 2002, Intertemporal CAPM and the Cross-Section of Stock Returns, Working paper.

[16] Chen, Zhanhui, and Ralitsa Petkova, 2012, Does Idiosyncratic Volatility Proxy for Risk Exposure? Review of Financial Studies 25, 2745-2787.

[17] Diether, Karl, Christopher Malloy, and Anna Scherbina, 2002, Differences of Opinion and the Cross-Section of Returns, Journal of Finance 57, 2113-2141.

[18] Duarte, Jefferson, Avraham Kamara, Stephan Siegel, Celine Sun, 2012, The Common Components of Idiosyncratic Volatility, Working paper.

[19] Fama, Eugene F., and Kenneth R. French, 1993, Common Risk Factors in the Returns on Stocks and Bonds, Journal of Financial Economics 33, 3-56.

[20] Fama, Eugene F., and Kenneth R. French, 1997, Industry Costs of Equity, Journal of Financial Economics 43, 153-193. 
[21] Gao, Xiaohui, and Jay R. Ritter, 2010, The Marketing of Seasoned Equity Offerings, Journal of Financial Economics 97, 33-52.

[22] Grullon, Gustavo, Evgeny Lyandres, and Alexei Zhdanov, 2012, Real Options, Volatility, and Stock Returns, Journal of Finance 67, 1499-1537.

[23] Johnson, Timothy C., 2004, Forecast Dispersion and the Cross-Section of Expected Returns, Journal of Finance 59, 1957-1978.

[24] Lu, Hai, Kevin Q. Wang, and Xiaolu Wang, 2013, Price Shocks, News Disclosures, and Asymmetric Drifts, Working paper.

[25] Kelly, Bryan, Hanno Lustig, and Stijn van Neuwerburgh, 2013, The Volatility Factor Structure, Working paper.

[26] Mitton, Todd, and Keith Vorkink, 2007, Equilibrium Underdiversification and the Preference for Skewness, Review of Financial Studies 20, 1255-1288.

[27] Nagel, Stefan, 2005, Short Sales, Institutional Investors, and the Cross-Section of Stock Returns, Journal of Financial Economics 78, 277-309.

[28] Newey, Whitney K., and Kenneth D. West, 1987, A Simple Positive Semi-Definite Heteroskedasticity and Autocorrelation Consistent Covariance Matrix, Econometrica $55,703-708$.

[29] Ohlson, James A., 1980, Financial Ratios and the Probabilistic Prediction of Bankruptcy, Journal of Accounting Research 18, 109-131. 


\section{A Data Appendix}

The variables are arranged in the alphabetical order according to the abbreviated variable name used in the tables.

AV (average volatility) - following Chen and Petkova, I compute average volatility by summing squared daily returns and the doubled products of today and yesterday returns in each firm-month and then averaging this sum for all firms in a month. The innovations to the average volatility are from the VAR with market returns, SMB, HML, AV, and average correlation between all stocks in a month.

$\boldsymbol{\beta}_{A V}$ (average volatility beta) - the loading on the innovations to average volatility (see above for the definition) from

$$
\operatorname{Ret}_{t}-R F_{t}=\alpha+\beta \cdot\left(M K T_{t}-R F_{t}\right)+\beta_{A V} \cdot A V_{t}
$$

When I compute the average volatility betas with respect to the traded factor, I form the trading factor as the fitted part from the regression of the AV innovations on the excess returns to the quintile portfolios, pre-sorted on past sensitivity to innovations in average volatility. The sensitivities are estimated in each firm-month by estimating (A-1) using the firm's returns in months t-1 to t-36.

$\boldsymbol{\beta}_{S R}$ and $\boldsymbol{\beta}_{L R}$ (short-run and long-run volatility betas) - the loadings on innovations to short-run and long-run market volatility components (see C-GARCH below) from

$$
\operatorname{Ret}_{t}-R F_{t}=\alpha+\beta \cdot\left(M K T_{t}-R F_{t}\right)+\beta_{L R} \cdot L R_{t}+\beta_{S R} \cdot S R_{t}
$$

Following Adrian and Rosenberg (2008), I compute monthly innovations to the shortrun and long-run volatility components in the following way: in each day of the market, I 
compute the change in the volatility forecast compared to the volatility forecast 21 trading days ago, and sum those values up within each month to arrive at monthly innovations.

When I need to compute the volatility betas with respect to traded factors, I form the traded factors in the following way. First, for each firm-month, I measure past exposures to the innovations (SR and LR), estimating regression (A-2) using the firm's returns between months t-1 and t-36. Then, I sort firms into quintiles based on the two sensitivities. Valueweighted returns to the quintile portfolios serve as the base assets for the factor-mimicking regressions. The factor-mimicking regressions regress the monthly innovations (SR and LR) on the monthly excess returns to the quintile portfolios formed based on the past sensitivities to the respective innovation. The traded factor is then the fitted part of the factor-mimicking regression less the constant.

CVEarn/CVCFO (earnings/cash flows volatility) - coefficient of variation (standard deviation over the average) of quarterly earnings/cash flows measured in the past twelve quarters. Earnings are EPS (epspiq over prccq lagged by one quarter). Cash flows are operating income before depreciation (oibdpq) less the change in current assets (actq) plus the change in current liabilities (lctq) less the change in short-term debt (dlcq) plus the change in cash (cheq). The cash flows are scaled by average total assets (atq) in the past two years. All variables are from the Compustat quarterly file.

C-GARCH (Component GARCH) - following Adrian and Rosenberg (2008), I estimate

$$
\begin{gathered}
M K T_{t+1}-R F_{t+1}=\theta_{1}+\theta_{2} \cdot s_{t}+\theta_{3} \cdot l_{t}+\sqrt{\nu_{t}} \cdot \epsilon_{t+1} \\
\ln \left(\sqrt{\nu_{t}}\right)=s_{t}+l_{t} \\
s_{t}=\theta_{4} \cdot s_{t-1}+\theta_{5} \cdot \epsilon_{t}+\theta_{6} \cdot\left(\left|\epsilon_{t}\right|-\sqrt{2 / \pi}\right)
\end{gathered}
$$




$$
l_{t}=\theta_{7}+\theta_{8} \cdot l_{t-1}+\theta_{9} \cdot \epsilon_{t}+\theta_{10} \cdot\left(\left|\epsilon_{t}\right|-\sqrt{2 / \pi}\right)
$$

where $s_{t}$ is the short-run volatility component and $l_{t}$ is the long-run volatility component. Using daily data from July 3, 1962, to December 31, 2012, the coefficients are estimated as (standard errors in parentheses)

$$
\begin{gathered}
M K T_{t+1}-R F_{t+1}=\underset{(0.014)}{0.014}-\underset{(0.128)}{1.410} \cdot s_{t}+\underset{(0.020)}{0.022} \cdot l_{t}+\sqrt{\nu_{t}} \cdot \epsilon_{t+1} \\
\ln \left(\sqrt{\nu_{t}}\right)=s_{t}+l_{t} \\
s_{t}=\underset{(0.036)}{0.366} \cdot s_{t-1}-\underset{(0.025)}{0.068} \cdot \epsilon_{t}-\underset{(0.004)}{0.012} \cdot\left(\left|\epsilon_{t}\right|-\sqrt{2 / \pi}\right) \\
l_{t}=-\underset{(0.002)}{0.052}+\underset{(0.001)}{0.989} \cdot l_{t-1}-\underset{(0.003)}{0.036} \cdot \epsilon_{t}+\underset{(0.002)}{0.065} \cdot\left(\left|\epsilon_{t}\right|-\sqrt{2 / \pi}\right)
\end{gathered}
$$

Disp (analyst forecast dispersion) - the standard deviation of all outstanding earnings-per-share forecasts for the current fiscal year scaled by the absolute value of the outstanding earnings forecast (zero-mean forecasts and forecasts by only one analyst excluded). Earnings forecasts are from the IBES Summary file.

Error (analyst forecast error) - the absolute value of the difference between the one-year-ahead consensus forecast and actual earnings divided by actual earnings. All variables are from the IBES Summary file.

ES (expected skewness) - the expected value from

$$
\begin{aligned}
\text { ISkew }_{t}=\gamma_{0} & +\gamma_{1} \cdot \text { ISkew }_{t-60}+\gamma_{2} \text { IVol }_{t-60}+\gamma_{3} \cdot \text { Mom }_{t-60}+\gamma_{4} \cdot \text { Turn }_{t-60}+ \\
& +\gamma_{5} \cdot \text { NASD }_{t-60}+\gamma_{6} \cdot \text { Small }_{t-60}+\gamma_{7} \cdot \text { Med }_{t-60}+\Gamma \cdot \text { IndDum }
\end{aligned}
$$

The regression is performed in cross-section every month. ISkew is idiosyncratic skewness, computed from daily firm-level residuals $(\epsilon)$ of the Fama-French model in the past 60 
months. ISkew is scaled by idiosyncratic volatility (IVol), computed the same way in the same period, raised to the power of $3 / 2$ :

$$
I \text { Skew }=\frac{\sum_{t \in D} \epsilon_{t}^{3}}{\left(\sum_{t \in D} \epsilon_{t}^{2}\right)^{3 / 2}}
$$

where $\mathrm{D}$ is the set of non-missing daily returns in the past 60 months. IVol on the righthand side of (A-2) is, as above, $I V o l=\sum_{t \in D} \epsilon_{t}^{2}$. Mom is cumulative monthly return in the past 12 months excluding the most recent one, Turn is average monthly turnover in the past year. NASD is NASDAQ dummy - 1 if the firm is from NASDAQ (exchcd from CRSP events file is equal to 3), and 0 otherwise. Small is small firms dummy - 1 if the firm is from the bottom three size deciles, 0 otherwise. Med is medium firms dummy - 1 if the firm is in one of the size deciles between fourth and seventh, 0 otherwise. Ind are industry dummies - 1 if the firm belongs to a certain industry, 0 otherwise. The industries are 30 industries from Fama and French (1997).

Fee (estimated shorting fee) - the estimate of shorting fee from Boehme, Danielsen, and Sorescu (2006):

$$
\begin{array}{r}
\text { Fee }=0.07834+0.05438 \cdot V R S I-0.00664 \cdot V R S I^{2}+0.0003820 \cdot V R S I^{3}-0.5908 \cdot \text { Option }+ \\
\quad+0.2587 \cdot \text { Option } \cdot V R S I-0.02713 \cdot \text { Option } \cdot V R S I^{2}+0.0007583 \cdot \text { Option } \cdot V R S I^{3}
\end{array}
$$

where $V R S I$ is the vicile rank of RSI ( 1 if the firm is in the bottom $5 \%$ in terms of RSI, 2 if the firm is between the 5 th and 10th percentile, etc.) and Option is the dummy for presence of a listed option on the stock - 1 if an option on the stock has non-zero trading volume in this month, 0 otherwise. The trading volume for options is from OptionMetrics.

ITA (investment-to-assets) - the change in capital expenditures (capx item from Compustat) over the previous year divided by total assets (at item from Compustat) in the previous year. 
IO (institutional ownership) - the sum of institutional holdings from Thompson Financial 13F database, divided by the shares outstanding from CRSP. All stocks below the 20th NYSE/AMEX size percentile are dropped. If the stock is not dropped, appears on CRSP, but not on Thompson Financial 13Fs, it is assumed to have zero IO.

IVol (idiosyncratic volatility) - the standard deviation of residuals from the FamaFrench model, fitted to the daily data for each month (at least 15 valid observations are required).

Max (maximum daily return) - maximum daily return (from CRSP) in the previous month.

MB (market-to-book) - equity value (item \#25 times item \#199) divided by book equity (item \#60) plus deferred taxes (item \#74), all items from Compustat annual.

Min (minimum daily return) - minimum daily return (from CRSP) in the previous month. In portfolio sorts, the minimum return is multiplied by -1 so that "high minimum return" meant "very negative minimum return".

O-score - the probability of bankruptcy measure from Ohlson (1980), computed as

$$
\begin{aligned}
O= & -1.32-0.407 \cdot \ln T A+6.03 \cdot \frac{T L}{T A}-1.43 \cdot \frac{W C}{T A}+0.076 \cdot \frac{C L}{C A}-1.72 \cdot I(T L>T A) \\
& -2.37 \cdot \frac{N I}{T A}-1.83 \cdot \frac{F F O}{T A}+0.285 \cdot I\left(N I<0 \& N I_{-1}<0\right)-0.521 \cdot \frac{N I-N I_{-1}}{|N I|+\left|N I_{-1}\right|},
\end{aligned}
$$

where $T A$ is the book value of total assets (Compustat item at), $T L$ is the book value of total liabilities (lt), $W C$ is working capital (wcap), $C L$ are current liabilities (lct), $C A$ are current assets (act), $N I$ is net income (ni), $N I_{-1}$ is the previous year net income, FFO are funds from operation (pi plus dp), $I(T L>T A$ ) is the dummy variable equal to one if the book value of total liabilities exceeds the book value of total assets, and equal to zero otherwise, $I\left(N I<0 \& N I_{-1}<0\right)$ is the dummy variable equal to one if the net income 
was negative in the two most recent years, and equal to zero otherwise.

Prob (probability to be on special) - defined as in D'Avolio (2002) and Ali and Trombley (2006)

$$
\begin{gathered}
S h=\frac{e^{y}}{1+e^{y}}, \\
y=-0.46 \cdot \log (\text { Size })-2.8 \cdot \text { Inst }+1.59 \cdot \text { Turn }-0.09 \cdot \frac{C F}{T A}+0.86 \cdot \text { IPO }+0.41 \cdot \text { Glam }
\end{gathered}
$$

In the equation above, Size is defined as shares outstanding times the price per share and measured in millions, Inst is IO, Turn is monthly turnover, defined as the trading volume over shares outstanding, CF is cash flow defined as operating income before depreciation (oiadp plus dp) less non-depreciation accruals, which are change in current assets (act) less change in current liabilities (lct) plus change in short-term debt (dlc) less change in cash (che), TA are total assets (at), IPO is the dummy variable equal to 1 if the stock first appeared on CRSP 12 or less months ago, and Glam is the dummy variable equal to 1 for three top market-to-book deciles. All items in the definitions of CF and TA are from the Compustat annual file.

Rating (credit rating) - Standard and Poor's rating (spdr variable in the Compustat quarterly file). The credit rating is coded as $1=\mathrm{AAA}, 2=\mathrm{AA}+, 3=\mathrm{AA}, \ldots, 21=\mathrm{C}, 22=\mathrm{D}$.

RD/TA (R\&D-to-assets) - research-and-development expenditures (xrd item from Compustat) divided by total assets (at item from Compustat) in the previous year.

Realized (realized market volatility) - the square root of the average squared daily return to the market portfolio (CRSP value-weighted index) within each given month.

RI (residual IO) - the residual $(\epsilon)$ from the logistic regression of IO on log Size and its square

$$
\log \left(\frac{\text { Inst }}{1-\text { Inst }}\right)=\gamma_{0}+\gamma_{1} \cdot \log (\text { Size })+\gamma_{2} \cdot \log ^{2}(\text { Size })+\epsilon
$$


RSI (residual short interest) - outstanding shorts reported by NYSE and NASDAQ divided by the number of shares outstanding. The data are monthly and reported on the 15th calendar day of each month.

SG (sales growth) - the change in sales (sale item from Compustat) in percentage of last year sales: $S G_{t}=\frac{\text { Sales }_{t}-\text { Sales }_{t-1}}{\text { Sales }_{t-1}}$,

Size (market cap) - shares outstanding times price, both from the CRSP monthly returns file.

SUE flex is the slope $\left(\gamma_{2}\right)$ from the firm-by-firm regression of earnings announcement returns on SUE squared (controlling for the level of SUE):

$$
C A R_{t}=\gamma_{0}+\gamma_{1} \cdot S U E_{t}+\gamma_{2} \cdot S U E_{t}^{2}
$$

The regression uses data from quarters $t$ - 1 to $t$-20 (at least 12 valid observations are required). Earnings announcement days are from Compustat quarterly file. Cumulative abnormal returns (CAR) are computed in the three days before, during, and after announcement using CAPM. The CAPM beta is estimated using daily returns in the year before the announcement. SUE is the difference between the announced EPS (epspiq over prccq lagged by one quarter) and average EPS in the past eight quarters, scaled by the standard deviation of EPS in the past eight quarters.

Size (market cap) - shares outstanding times price, both from the CRSP monthly returns file.

TARCH (expected market volatility) -from the $\operatorname{TARCH}(1,1)$ model (see Glosten, Jagannathan, and Runkle, 1993) fitted to monthly returns to the CRSP value-weighted index:

$$
\operatorname{Ret}_{t}^{C R S P}=\gamma_{0}+\gamma_{1} \cdot \operatorname{Ret}_{t-1}^{C R S P}+\epsilon_{t}, \quad \sigma_{t}^{2}=c_{0}+c_{1} \sigma_{t-1}^{2}+c_{2} \epsilon_{t-1}^{2}+c_{3} \cdot I\left(\epsilon_{t-1}<0\right)
$$


The regression estimated for the full sample. I take the square root out of the volatility forecast to be consistent with my measure of idiosyncratic volatility.

Turn (turnover) - trading volume divided by shares outstanding (both from CRSP monthly data). The monthly turnover is then averaged in each calendar year with at least 5 valid observations. To make comparisons across exchanges more meaningful, I adjust NASDAQ volume for the double counting following Gao and Ritter (2010): NASDAQ volume is divided by 2 for the period from 1983 to January 2001, by 1.8 for the rest of 2001, by 1.6 for 2002-2003, and is unchanged after that. A firm is classified as a NASDAQ firm if its CRSP events file listing indicator - exchcd - is equal to 3.

VIX - the VIX index, defined as the implied volatility of at-the-money options on S\&P 100 (current ticker VXO). VIX is computed by CBOE and obtained from WRDS. 


\section{Table 1. FVIX Factor as an ICAPM Factor}

Panel A reports the correlations between FVIX and the VIX and its change on the left, and the alphas and Fama-French betas of the FVIX factor on the left. The FVIX factor is the fitted value less the constant from the regression of daily changes in the VIX index on the daily excess returns to the volatility sensitivity quintiles (please refer to Section 2 for more details). The daily returns of the FVIX factor are then cumulated to the monthly level.

Panel B presents the slopes from the regressions of the business cycle variables (NBER recession dummy, the VIX index, the $\operatorname{TARCH}(1,1)$ forecast of market volatility, and the realized volatility, which the sum of squared daily returns) on the FVIX factor returns. The regression with the NBER dummy is the probit regression. The numbers in the first row are the number of months by which I lag the FVIX factor returns in each column. The slopes (with the exception of the probit regression) indicate the change in the business cycles variables (in percentage points) in response to $1 \%$ return to the FVIX factor. The t-statistics use Newey-West (1987) correction for heteroscedasticity and autocorrelation. The sample period is from January 1986 to December 2010.

\section{Panel A. FVIX as Factor-Mimicking Portfolio}

Correlations

FVIX Factor

\begin{tabular}{lccclccc}
\hline \hline & FVIX & $\boldsymbol{\Delta}$ VIX & VIX & & Raw & CAPM & FF \\
\hline \hline FVIX & 1 & 0.653 & 0.352 & $\boldsymbol{\alpha}$ & -1.215 & -0.461 & -0.455 \\
t-stat & & 14.9 & 6.49 & t-stat & -3.44 & -3.86 & -3.26 \\
\hline $\boldsymbol{\Delta}$ VIX & 0.653 & 1 & 0.288 & $\boldsymbol{\beta}_{M K T}$ & & -1.330 & -1.368 \\
t-stat & 14.9 & & 5.19 & t-stat & -29.5 & -26.9 \\
\hline VIX & 0.352 & 0.288 & 1 & $\boldsymbol{\beta}_{S M B}$ & & & 0.201 \\
t-stat & 6.49 & 5.19 & & t-stat & & 5.32 \\
\hline & & & & $\boldsymbol{\beta}_{H M L}$ & & -0.030 \\
& & & t-stat & & -0.49 \\
\hline \hline
\end{tabular}

Panel B. Business Cycle Variables Predicted by FVIX Factor Returns

\begin{tabular}{lrrrrrrrrr}
\hline \hline & $\mathbf{- 1 2}$ & $\mathbf{- 9}$ & $\mathbf{- 6}$ & $\mathbf{- 3}$ & $\mathbf{0}$ & $\mathbf{3}$ & $\mathbf{6}$ & $\mathbf{9}$ & $\mathbf{1 2}$ \\
\hline \hline NBER & 2.846 & 2.825 & 3.983 & 4.027 & 1.940 & -0.121 & -0.697 & 0.194 & 0.817 \\
t-stat & 1.92 & 1.94 & 2.81 & 2.91 & 1.41 & -0.08 & -0.47 & 0.13 & 0.58 \\
\hline VIX & 0.109 & 0.308 & 0.457 & 0.649 & 1.620 & -0.237 & -0.157 & 0.013 & -0.062 \\
t-stat & 0.39 & 0.99 & 1.47 & 1.87 & 4.49 & -0.73 & -0.44 & 0.04 & -0.26 \\
\hline TARCH & 0.370 & 0.415 & 0.603 & 0.860 & 0.891 & -0.206 & -0.175 & 0.013 & -0.004 \\
t-stat & 1.51 & 1.50 & 2.33 & 3.08 & 2.92 & -0.78 & -0.67 & 0.05 & -0.02 \\
\hline Realized & 0.269 & 0.439 & 0.724 & 0.760 & 2.166 & -0.004 & -0.183 & -0.007 & 0.071 \\
t-stat & 0.68 & 0.88 & 1.74 & 1.48 & 3.80 & -0.01 & -0.34 & -0.02 & 0.19 \\
\hline \hline
\end{tabular}




\section{Table 2. Lottery Likeness, Equity Option-Likeness, and Firm-Specific Uncertainty}

Panel A reports median values of several measures of firm-specific uncertainty - idiosyncratic volatility (IVol), analyst disagreement (Disp), analyst forecast error (Error), volatility of cash flows (CVCFO) and earnings (CVEarn) - across the quintiles formed from the sorts on the maximum daily return in the past month (left part) and expected idiosyncratic skewness (right part). Panel B reports, for the same quintiles, median values of growth options measures: market capitalization (Size), market-to-book $(\mathrm{MB})$, the ratio of R\&D expenses to total assets $(\mathrm{RD} / \mathrm{TA})$, future sales growth $\left(S G_{t+1}\right)$, and future investmentto-assets ratio $\left(I T A_{t+1}\right)$. Panel $\mathrm{B}$ also looks at the measures of option-likeness created by risky debt: credit rating (Rating) and Ohlson's (1980) O-score, as well as the general measure of option-likeness from Grullon et al. (2012) - the convexity of the earnings-return relation (SUE flex). Credit rating is coded numerically assuming that AAA $=1$, AA $+=2$, etc. Detailed definitions of all variables are in the Data Appendix. The $t$-statistics (in italics) use the Newey-West (1987) correction for heteroskedasticity and autocorrelation. The sample period is from January 1986 to December 2010. The sample excludes the stocks with per share price less than $\$ 5$ on the portfolio formation date.

Panel A. Firm-Specific Uncertainty and Option Likeness

A1. Past Maximum Returns

A2. Expected Skewness

\begin{tabular}{lcccccclcccccc}
\hline \hline & Low & Max2 & Max3 & Max4 & High & H-L & & Low & ES2 & ES3 & ES4 & High & H-L \\
\hline IVol & 1.163 & 1.597 & 1.894 & 2.252 & 3.095 & 1.932 & IVol & 1.337 & 1.607 & 1.696 & 1.902 & 2.273 & 0.936 \\
t-stat & 30.9 & 30.0 & 31.1 & 32.3 & 30.5 & 25.6 & t-stat & 28.3 & 30.5 & 30.5 & 31.5 & 31.9 & 23.4 \\
\hline Disp & 3.988 & 4.268 & 4.910 & 5.470 & 7.807 & 3.819 & Disp & 4.033 & 5.438 & 5.587 & 5.039 & 6.351 & 2.318 \\
t-stat & 23.0 & 22.1 & 18.7 & 24.9 & 23.8 & 15.8 & t-stat & 22.9 & 15.9 & 15.3 & 16.0 & 18.4 & 6.67 \\
\hline Error & 7.685 & 8.294 & 9.850 & 12.30 & 17.72 & 10.035 & Error & 8.736 & 8.769 & 9.937 & 10.68 & 14.82 & 6.079 \\
t-stat & 23.7 & 21.8 & 21.4 & 20.3 & 21.5 & 16.5 & t-stat & 21.5 & 23.1 & 19.0 & 20.7 & 22.1 & 13.4 \\
\hline CVEarn & 0.834 & 0.844 & 0.917 & 1.016 & 1.232 & 0.398 & CVEarn & 0.715 & 0.826 & 0.933 & 1.082 & 1.189 & 0.474 \\
t-stat & 34.7 & 30.9 & 31.8 & 27.9 & 38.2 & 15.5 & t-stat & 20.0 & 26.9 & 24.1 & 21.4 & 49.4 & 14.0 \\
\hline CVCFO & 1.051 & 1.051 & 1.133 & 1.245 & 1.469 & 0.417 & CVCFO & 0.829 & 0.908 & 1.020 & 1.154 & 1.443 & 0.614 \\
t-stat & 63.3 & 61.6 & 71.0 & 75.8 & 72.1 & 24.1 & t-stat & 32.4 & 39.3 & 53.1 & 61.2 & 59.1 & 21.4 \\
\hline \hline
\end{tabular}


Panel B. Lottery Likeness and Option Likeness

B1. Past Maximum Returns

B2. Expected Skewness

\begin{tabular}{|c|c|c|c|c|c|c|c|c|c|c|c|c|c|}
\hline & Low & Max2 & Max3 & Max4 & High & H-L & & Low & ES2 & ES3 & ES4 & High & H-L \\
\hline Size & 0.638 & $\begin{array}{l}0.573 \\
\end{array}$ & 0.400 & 0.282 & 0.181 & -0.458 & $\overline{\text { Size }}$ & 1.709 & 1.488 & 1.084 & $\begin{array}{l}0.373 \\
\end{array}$ & 0.115 & -1.594 \\
\hline t-stat & 8.37 & 12.7 & 13.3 & 12.3 & 10.9 & -6.83 & t-stat & 10.9 & 11.7 & 12.6 & 12.3 & 11.7 & -10.8 \\
\hline MB & 1.920 & 1.996 & 2.010 & 2.050 & 2.268 & 0.348 & MB & 2.160 & 2.078 & 1.981 & 1.817 & 1.750 & -0.410 \\
\hline t-stat & 34.6 & 49.7 & 49.0 & 46.2 & 30.9 & 4.45 & t-stat & 42.9 & 40.6 & 37.4 & 38.3 & 39.7 & -17.6 \\
\hline $\mathrm{RD} / \mathrm{TA}$ & 0.020 & 0.023 & 0.026 & 0.034 & 0.058 & 0.037 & $\mathrm{RD} / \mathrm{TA}$ & 0.038 & 0.032 & 0.034 & 0.042 & 0.047 & 0.009 \\
\hline t-stat & 30.9 & 33.3 & 43.6 & 53.0 & 24.0 & 12.9 & t-stat & 39.5 & 50.0 & 47.4 & 33.7 & 22.3 & 3.94 \\
\hline $\mathrm{SG}_{\mathrm{t}+1}$ & 0.061 & 0.070 & 0.081 & 0.092 & 0.101 & 0.040 & $\mathrm{SG}_{\mathrm{t}+1}$ & 0.075 & 0.086 & 0.095 & 0.099 & 0.095 & 0.020 \\
\hline t-stat & 13.7 & 13.5 & 14.4 & 14.8 & 13.3 & 8.78 & t-stat & 12.6 & 14.0 & 14.6 & 16.1 & 15.7 & 6.36 \\
\hline ITA $_{t+1}$ & 0.046 & 0.056 & 0.063 & 0.067 & 0.063 & 0.018 & ITA $_{t+1}$ & 0.055 & 0.067 & 0.068 & 0.065 & 0.059 & 0.005 \\
\hline t-stat & 27.8 & 29.1 & 27.2 & 24.1 & 20.1 & 7.49 & t-stat & 19.2 & 31.6 & 22.2 & 18.8 & 21.2 & 2.28 \\
\hline Rating & 9.393 & 9.554 & 10.508 & 12.079 & 13.602 & 4.209 & Rating & 8.612 & 8.965 & 9.570 & 11.069 & 13.288 & 4.676 \\
\hline t-stat & 42.6 & 46.5 & 47.6 & 76.1 & 210.7 & 21.4 & t-stat & 42.9 & 40.5 & 54.4 & 50.3 & 131.7 & 24.1 \\
\hline O-score & -1.858 & -1.940 & -1.903 & -1.785 & -1.402 & 0.455 & O-score & -2.283 & -2.083 & -1.956 & -1.866 & -1.469 & 0.814 \\
\hline t-stat & -46.3 & -57.2 & -59.2 & -56.6 & -40.3 & 12.6 & t-stat & -68.0 & -55.4 & -48.5 & -43.3 & -34.4 & 13.6 \\
\hline SUE flex & 0.037 & 0.042 & 0.046 & 0.055 & 0.060 & 0.023 & SUE flex & 0.024 & 0.025 & 0.035 & 0.035 & 0.079 & 0.055 \\
\hline t-stat & 9.43 & 10.5 & 12.0 & 15.0 & 18.7 & 5.93 & t-stat & 4.44 & 5.50 & 7.57 & 10.6 & 17.7 & 8.51 \\
\hline
\end{tabular}




\section{Table 3. Lottery Likeness, Aggregate Volatility Risk, and the Cross-Section of Returns}

The table reports value-weighted alphas from the CAPM and the Fama-French model (FF), as well as alphas and FVIX betas from the two-factor ICAPM with the market factor and FVIX and the four-factor model with the three Fama-French factors and FVIX (FF4). The models are fitted to the quintile portfolios sorted on the maximum daily return in the past month (Panel A) and expected idiosyncratic skewness (Panel B). FVIX is the factor-mimicking portfolio that tracks daily changes in VIX. The $t$-statistics (in italics) use the Newey-West (1987) correction for heteroskedasticity and autocorrelation. The sample period is from January 1986 to December 2010. The sample excludes the stocks with per share price less than $\$ 5$ on the portfolio formation date.

Panel A. Past Maximum Returns

Panel B. Expected Skewness

\begin{tabular}{|c|c|c|c|c|c|c|c|c|c|c|c|c|c|}
\hline & Low & Max2 & Max3 & $\operatorname{Max} 4$ & High & L-H & & Low & ES2 & ES3 & ES4 & High & L-H \\
\hline $\boldsymbol{\alpha}_{C A P M}$ & 0.231 & 0.232 & 0.062 & -0.087 & -0.369 & 0.600 & $\boldsymbol{\alpha}_{C A P M}$ & 0.160 & -0.030 & -0.092 & -0.050 & -0.378 & 0.539 \\
\hline t-stat & 1.94 & 2.39 & 0.63 & -0.89 & -2.35 & 2.30 & t-stat & 2.12 & -0.30 & -0.86 & -0.25 & -1.77 & 2.21 \\
\hline $\boldsymbol{\alpha}_{F F}$ & 0.140 & 0.166 & 0.013 & -0.115 & -0.279 & 0.419 & C & 0.159 & -0.094 & -0.082 & 0.017 & -0.443 & 0.602 \\
\hline t-stat & 1.42 & 2.26 & 0.17 & -1.11 & -2.32 & 2.08 & t-stat & 2.22 & -1.19 & -0.72 & 0.09 & -2.29 & 2.87 \\
\hline $\boldsymbol{\alpha}_{I C A P}$ & -0.061 & -0.010 & -0.089 & -0.056 & 0.051 & -0.112 & 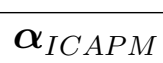 & -0.045 & -0.130 & -0.134 & 0.110 & 0.037 & -0.082 \\
\hline t-stat & -0.54 & -0.12 & -0.88 & -0.49 & 0.35 & -0.47 & t-stat & -0.54 & -1.34 & -1.20 & 0.53 & 0.15 & -0.29 \\
\hline $\boldsymbol{\beta}_{F V I X}$ & -0.633 & -0.524 & -0.328 & 0.068 & 0.912 & -1.544 & $\boldsymbol{\beta}_{F V I X}$ & -0.423 & -0.206 & -0.087 & 0.330 & 0.857 & -1.280 \\
\hline t-stat & -3.45 & -3.35 & -2.40 & 0.63 & 3.24 & -3.38 & t-stat & -3.73 & -1.64 & -1.05 & 1.56 & 3.28 & -3.54 \\
\hline $\boldsymbol{\alpha}_{F F 4}$ & -0.062 & 0.007 & -0.094 & -0.087 & -0.030 & -0.031 & $\boldsymbol{\alpha}_{F F 4}$ & 0.006 & -0.125 & -0.137 & 0.101 & -0.317 & 0.323 \\
\hline t-stat & -0.67 & 0.10 & -1.23 & -0.79 & -0.28 & -0.17 & t-stat & 0.08 & -1.49 & -1.20 & 0.46 & -1.54 & 1.53 \\
\hline $\boldsymbol{\beta}_{F V I X}$ & -0.443 & -0.349 & -0.235 & 0.061 & 0.546 & -0.989 & $\boldsymbol{\beta}_{F V I X}$ & -0.312 & -0.063 & -0.113 & 0.170 & 0.256 & -0.568 \\
\hline t-stat & -4.50 & -4.84 & -3.00 & 0.75 & 3.10 & -3.76 & t-stat & -4.91 & -0.96 & -1.32 & 0.86 & 2.38 & -4.31 \\
\hline
\end{tabular}




\section{Table 4. Lottery Likeness, Option Likeness, and Aggregate Volatility Risk}

Panel A1 presents CAPM alphas, ICAPM alphas, and FVIX betas for the arbitrage portfolios that buy firms with low values of the maximum daily return in the previous month and shorts firms with high values of maximum daily return in the past month. The arbitrage portfolios are formed separately in each market-to-book quintile. Panel A2 repeats Panel A1 replacing the low-minus-high maximum return portfolio by the portfolio that buys firms with low and shorts firms with high expected idiosyncratic skewness. Panel $\mathrm{B}$ repeats the analysis in Panel A using credit rating instead of market-to-book. FVIX is the factor-mimicking portfolio that tracks daily changes in VIX. The $t$-statistics (in italics) use the Newey-West (1987) correction for heteroskedasticity and autocorrelation. The sample period is from January 1986 to December 2010. The sample excludes the stocks with per share price less than $\$ 5$ on the portfolio formation date.

\section{Panel A. Maximum/Skewness Effect, Growth Options, and Aggregate Volatility Risk}

A1. Maximum Effect

A2. Skewness Effect

\begin{tabular}{lcccclcccc}
\hline \hline & Value & Neut & Growth & G-V & & Value & Neut & Growth & G-V \\
\hline \hline $\boldsymbol{\alpha}_{C A P M}$ & 0.491 & 0.734 & 1.107 & 0.616 & $\boldsymbol{\alpha}_{C A P M}$ & -0.212 & 0.092 & 0.366 & 0.577 \\
t-stat & 3.54 & 4.18 & 4.17 & 2.75 & t-stat & -1.53 & 0.73 & 1.60 & 3.02 \\
\hline $\boldsymbol{\alpha}_{I C A P M}$ & 0.222 & 0.265 & 0.383 & 0.161 & $\boldsymbol{\alpha}_{I C A P M}$ & -0.243 & -0.184 & -0.004 & 0.240 \\
t-stat & 1.36 & 1.31 & 1.42 & 0.66 & t-stat & -1.71 & -1.33 & -0.02 & 1.48 \\
\hline $\boldsymbol{\beta}_{F V I X}$ & -0.583 & -1.017 & -1.570 & -0.987 & $\boldsymbol{\beta}_{F V I X}$ & -0.069 & -0.600 & -0.802 & -0.733 \\
t-stat & -3.32 & -3.85 & -3.07 & -2.53 & t-stat & -0.49 & -2.72 & -2.39 & -3.08 \\
\hline \hline
\end{tabular}

\section{Panel B. Maximum/Skewness Effect, Credit Rating, and Aggregate Volatility Risk}

B1. Maximum Effect

B2. Skewness Effect

\begin{tabular}{lcccclcccc}
\hline \hline & Best & Med & Worst & W-B & & Best & Med & Worst & W-B \\
\hline \hline $\boldsymbol{\alpha}_{C A P M}$ & 0.096 & 0.556 & 1.201 & 1.105 & $\boldsymbol{\alpha}_{C A P M}$ & 0.163 & 0.370 & 0.970 & 0.808 \\
t-stat & 0.45 & 1.81 & 2.75 & 2.75 & t-stat & 0.85 & 1.42 & 2.25 & 2.02 \\
\hline $\boldsymbol{\alpha}_{I C A P M}$ & -0.202 & -0.125 & 0.117 & 0.318 & $\boldsymbol{\alpha}_{I C A P M}$ & -0.002 & 0.092 & 0.400 & 0.402 \\
t-stat & -0.84 & -0.39 & 0.30 & 0.82 & t-stat & -0.01 & 0.33 & 0.89 & 0.89 \\
\hline $\boldsymbol{\beta}_{F V I X}$ & -0.645 & -1.479 & -2.353 & -1.707 & $\boldsymbol{\beta}_{F V I X}$ & -0.340 & -0.572 & -1.177 & -0.837 \\
t-stat & -2.92 & -4.13 & -8.29 & -7.62 & t-stat & -1.87 & -3.07 & -2.44 & -1.68 \\
\hline \hline
\end{tabular}




\section{Table 5. Lottery Likeness, Short-Sale Constraints, and Aggregate Volatility Risk}

The first part of the table (Panels A and B) present the median values of several shortsale constraints measures across the quintiles formed from the sorts on the maximum daily return in the past month (Panel A) and expected idiosyncratic skewness (Panel B). The short-sale constraints measures are institutional ownership (IO), relative short interest (RSI), estimated shorting fee (Fee), and estimated probability to be on special (Prob). Detailed definitions of all variables are in the Data Appendix.

The second part of the table (Panels C and D) presents CAPM alphas, ICAPM alphas, and FVIX betas for the arbitrage portfolios that buy firms with low values and shorts firms with high values of the maximum daily return in the previous month (left part) or expected idiosyncratic skewness (right part). The arbitrage portfolios are formed separately in each IO (Panel C) and RSI (Panel D) quintile. The IO quintiles are rebalanced quarterly, the RSI quintiles are rebalanced monthly. The $t$-statistics (in italics) use the Newey-West (1987) correction for heteroskedasticity and autocorrelation. The sample period is from January 1986 to December 2010. The sample excludes the stocks with per share price less than $\$ 5$ on the portfolio formation date.

Panel A. Maximum and Short-Sale Constraints

\begin{tabular}{lcccccc}
\hline \hline & Low & Max2 & Max3 & Max4 & High & L-H \\
\hline \hline IO & 18.69 & 17.23 & 18.07 & 18.49 & 16.71 & -1.986 \\
t-stat & 10.3 & 10.7 & 11.2 & 11.0 & 9.43 & -2.26 \\
\hline RSI & 0.217 & 0.303 & 0.385 & 0.468 & 0.523 & 0.306 \\
t-stat & 8.63 & 7.94 & 7.01 & 6.99 & 7.96 & 4.57 \\
\hline Fee & 0.246 & 0.261 & 0.270 & 0.283 & 0.309 & 0.063 \\
t-stat & 44.2 & 58.9 & 89.6 & 90.1 & 42.7 & 9.37 \\
\hline Prob & 3.886 & 4.002 & 4.599 & 5.513 & 7.640 & 3.754 \\
t-stat & 17.1 & 18.5 & 18.5 & 18.0 & 18.3 & 15.4 \\
\hline \hline
\end{tabular}

Panel B. Skewness and Short-Sale Constraints

\begin{tabular}{lrrrrrc}
\hline \hline & Low & ES2 & ES3 & ES4 & High & L-H \\
\hline \hline IO & 13.76 & 16.87 & 19.45 & 21.53 & 23.21 & 9.451 \\
t-stat & 6.61 & 8.32 & 8.99 & 14.4 & 14.7 & 9.72 \\
\hline RSI & 1.428 & 1.160 & 1.075 & 0.697 & 0.163 & -1.265 \\
t-stat & 7.62 & 7.33 & 6.87 & 5.37 & 13.0 & -7.17 \\
\hline Prob & 3.265 & 3.352 & 3.464 & 4.157 & 6.060 & 2.796 \\
t-stat & 16.7 & 18.3 & 17.4 & 17.0 & 18.8 & 13.4 \\
\hline Fee & 0.440 & 0.404 & 0.372 & 0.299 & 0.244 & -0.196 \\
t-stat & 35.3 & 52.5 & 48.4 & 71.1 & 79.9 & -17.0 \\
\hline \hline
\end{tabular}


Panel C. Maximum/Skewness Effect, Institutional Ownership, and Aggregate Volatility Risk

C1. Maximum Effect

C2. Skewness Effect

\begin{tabular}{lcccclcccc}
\hline \hline & Low & Med & High & L-H & & Low & Med & High & L-H \\
\hline \hline $\boldsymbol{\alpha}_{C A P M}$ & 0.954 & 0.625 & 0.471 & 0.483 & $\boldsymbol{\alpha}_{C A P M}$ & 0.344 & 0.144 & -0.089 & 0.433 \\
t-stat & 3.30 & 3.49 & 1.87 & 2.10 & t-stat & 1.84 & 1.14 & -0.68 & 2.63 \\
\hline $\boldsymbol{\alpha}_{I C A P M}$ & 0.246 & 0.227 & -0.042 & 0.288 & $\boldsymbol{\alpha}_{I C A P M}$ & -0.093 & -0.182 & -0.356 & 0.263 \\
t-stat & 1.13 & 1.61 & -0.18 & 1.42 & t-stat & -0.40 & -1.10 & -2.41 & 1.45 \\
\hline $\boldsymbol{\beta}_{F V I X}$ & -1.553 & -0.874 & -1.126 & -0.427 & $\boldsymbol{\beta}_{F V I X}$ & -0.901 & -0.673 & -0.549 & -0.352 \\
t-stat & -3.67 & -2.63 & -4.52 & -1.69 & t-stat & -2.62 & -2.94 & -2.93 & -1.93 \\
\hline \hline
\end{tabular}

Panel C. Maximum/Skewness Effect, Relative Short Interest, and Aggregate Volatility Risk

D1. Maximum Effect

D2. Skewness Effect

\begin{tabular}{lcccclcccc}
\hline \hline & Low & Med & High & H-L & & Low & Med & High & H-L \\
\hline \hline $\boldsymbol{\alpha}_{C A P M}$ & 0.321 & 0.545 & 0.948 & 0.627 & $\boldsymbol{\alpha}_{C A P M}$ & -0.006 & 0.098 & 0.399 & 0.405 \\
t-stat & 2.08 & 2.59 & 3.44 & 2.35 & t-stat & -0.04 & 0.53 & 1.72 & 1.86 \\
\hline $\boldsymbol{\alpha}_{C A P M}$ & 0.022 & -0.016 & 0.242 & 0.219 & $\boldsymbol{\alpha}_{I C A P M}$ & -0.295 & -0.437 & -0.161 & 0.134 \\
t-stat & 0.14 & -0.07 & 0.80 & 0.83 & t-stat & -1.84 & -1.52 & -0.48 & 0.44 \\
\hline $\boldsymbol{\beta}_{F V I X}$ & -0.628 & -1.180 & -1.485 & -0.856 & $\boldsymbol{\beta}_{F V I X}$ & -0.606 & -1.125 & -1.178 & -0.572 \\
t-stat & -5.68 & -3.05 & -2.82 & -1.86 & t-stat & -4.79 & -2.45 & -2.25 & -1.25 \\
\hline \hline
\end{tabular}




\section{Table 6. Past Minimum Returns, Equity Option-Likeness, and Firm-Specific Uncertainty}

Panel A reports median values of several measures of firm-specific uncertainty from Table 2 across the quintiles formed from the sorts on the minimum daily return in the past month (the minimum return is multiplied by -1). Panel B reports, for the same quintiles, median values of growth options measures from Table 2, as well as the measures of option-likeness created by risky debt and the general measure of option-likeness from Grullon et al. (2012). Credit rating is coded numerically assuming that $\mathrm{AAA}=1, \mathrm{AA}+=2$, etc. Detailed definitions of all variables are in the Data Appendix. The $t$-statistics (in italics) use the Newey-West (1987) correction for heteroskedasticity and autocorrelation. The sample period is from January 1986 to December 2010. The sample excludes the stocks with per share price less than $\$ 5$ on the portfolio formation date.

\section{Panel A. Past Minimum Return and Firm-Specific Uncertainty}

\begin{tabular}{lcccccc}
\hline \hline & Low & Min2 & Min3 & Min4 & High & H-L \\
\hline \hline IVol & 1.125 & 1.551 & 1.828 & 2.201 & 3.161 & 2.036 \\
t-stat & 30.2 & 29.0 & 31.2 & 30.6 & 29.3 & 25.1 \\
\hline Disp & 3.906 & 4.212 & 4.901 & 5.514 & 7.995 & 4.089 \\
t-stat & 23.1 & 22.4 & 16.2 & 22.3 & 24.0 & 15.3 \\
\hline Error & 7.290 & 8.230 & 9.923 & 12.48 & 18.32 & 11.031 \\
t-stat & 24.4 & 22.1 & 22.0 & 20.6 & 19.3 & 15.2 \\
\hline CVEarn & 0.818 & 0.848 & 0.939 & 1.037 & 1.204 & 0.386 \\
t-stat & 34.9 & 32.3 & 29.8 & 32.7 & 37.4 & 15.7 \\
\hline CVCFO & 1.027 & 1.041 & 1.143 & 1.263 & 1.462 & 0.435 \\
t-stat & 59.0 & 70.9 & 69.1 & 69.5 & 73.1 & 23.8 \\
\hline \hline
\end{tabular}


Panel B. Past Minimum Return and Option Likeness

\begin{tabular}{lcccccc}
\hline \hline & Low & Min2 & Min3 & Min4 & High & H-L \\
\hline \hline Size & 0.681 & 0.599 & 0.412 & 0.280 & 0.181 & -0.500 \\
t-stat & 8.5 & 12.9 & 13.6 & 12.9 & 10.7 & -7.01 \\
\hline MB & 1.938 & 1.997 & 1.981 & 2.024 & 2.275 & 0.337 \\
t-stat & 34.0 & 46.9 & 47.2 & 44.9 & 31.2 & 4.24 \\
\hline RD/TA & 0.021 & 0.023 & 0.025 & 0.034 & 0.057 & 0.037 \\
t-stat & 30.3 & 27.3 & 36.7 & 40.3 & 23.9 & 12.5 \\
\hline SG $_{\text {t+1 }}$ & 0.068 & 0.075 & 0.084 & 0.092 & 0.092 & 0.024 \\
t-stat & 15.5 & 14.6 & 14.9 & 14.3 & 12.0 & 5.17 \\
\hline ITA $+\mathbf{t}$ & 0.050 & 0.058 & 0.064 & 0.067 & 0.061 & 0.011 \\
t-stat & 27.6 & 28.7 & 26.0 & 24.0 & 19.7 & 4.71 \\
\hline Rating & 9.339 & 9.510 & 10.577 & 12.119 & 13.548 & 4.209 \\
t-stat & 42.3 & 51.0 & 49.5 & 81.3 & 195.7 & 21.6 \\
\hline O-score & -1.885 & -1.945 & -1.877 & -1.769 & -1.423 & 0.462 \\
t-stat & -49.0 & -57.4 & -57.8 & -58.5 & -40.0 & 11.5 \\
\hline SUE flex & 0.037 & 0.040 & 0.047 & 0.049 & 0.064 & 0.027 \\
t-stat & 9.66 & 11.0 & 12.9 & 15.4 & 17.6 & 7.43 \\
\hline \hline
\end{tabular}




\section{Table 7. The Minimum Effect and the Cross-Section of Returns}

Panel A reports value-weighted alphas from the CAPM and the Fama-French model (FF), as well as alphas and FVIX betas from the two-factor ICAPM with the market factor and FVIX and the four-factor model with the three Fama-French factors and FVIX (FF4). The models are fitted to the quintile portfolios sorted on the minimum daily return in the past month (multiplied by -1 ). Panel B presents CAPM alphas, ICAPM alphas, and FVIX betas for the arbitrage portfolios that buy firms with low values of the minimum daily return in the previous month and shorts firms with high values of minimum daily return in the past month. The arbitrage portfolios are formed separately in each marketto-book (Panel B1) or credit rating (Panel B2) quintile. FVIX is the factor-mimicking portfolio that tracks daily changes in VIX. The $t$-statistics (in italics) use the Newey-West (1987) correction for heteroskedasticity and autocorrelation. The sample period is from January 1986 to December 2010. The sample excludes the stocks with per share price less than $\$ 5$ on the portfolio formation date.

\section{Panel A. Minimum Effect}

\begin{tabular}{lcccccc}
\hline \hline & Low & Min2 & Min3 & Min4 & High & L-H \\
\hline \hline $\boldsymbol{\alpha}_{C A P M}$ & 0.100 & 0.101 & 0.173 & 0.073 & -0.472 & 0.572 \\
t-stat & 0.89 & 1.22 & 2.11 & 0.84 & -2.94 & 2.26 \\
\hline $\boldsymbol{\alpha}_{F F}$ & 0.037 & 0.035 & 0.105 & 0.041 & -0.416 & 0.453 \\
t-stat & 0.40 & 0.49 & 1.41 & 0.48 & -2.64 & 1.99 \\
\hline $\boldsymbol{\alpha}_{I C A P M}$ & -0.161 & -0.143 & 0.041 & 0.061 & -0.020 & -0.140 \\
t-stat & -1.52 & -1.68 & 0.53 & 0.73 & -0.15 & -0.62 \\
\hline $\boldsymbol{\beta}_{F V I X}$ & -0.566 & -0.530 & -0.286 & -0.028 & 0.980 & -1.546 \\
t-stat & -3.96 & -2.89 & -2.42 & -0.35 & 5.10 & -4.76 \\
\hline $\boldsymbol{\alpha}_{F F 4}$ & -0.129 & -0.116 & 0.018 & -0.018 & -0.141 & 0.012 \\
t-stat & -1.47 & -1.70 & 0.24 & -0.22 & -1.13 & 0.06 \\
\hline $\boldsymbol{\beta}_{F V I X}$ & -0.365 & -0.332 & -0.190 & -0.131 & 0.605 & -0.970 \\
t-stat & -3.91 & -3.65 & -2.86 & -1.65 & 4.97 & -4.91 \\
\hline \hline
\end{tabular}

Panel B. Minimum Effect and Equity Option-Likeness

\section{B1. Growth Options B2. Credit Rating}

\begin{tabular}{lcccclcccc}
\hline \hline & Value & Neut & Growth & G-V & & Best & Med & Worst & W-B \\
\hline \hline $\boldsymbol{\alpha}_{C A P M}$ & 0.033 & 0.227 & 0.831 & 0.799 & $\boldsymbol{\alpha}_{C A P M}$ & 0.013 & 0.617 & 0.978 & 0.965 \\
t-stat & 0.21 & 1.34 & 2.83 & 3.59 & t-stat & 0.06 & 1.77 & 2.95 & 2.68 \\
\hline $\boldsymbol{\alpha}_{I C A P M}$ & -0.279 & -0.258 & 0.135 & 0.414 & $\boldsymbol{\alpha}_{I C A P M}$ & -0.273 & -0.079 & 0.116 & 0.389 \\
t-stat & -1.62 & -1.45 & 0.47 & 1.80 & t-stat & -1.21 & -0.26 & 0.34 & 1.05 \\
\hline $\boldsymbol{\beta}_{F V I X}$ & -0.677 & -1.051 & -1.511 & -0.834 & $\boldsymbol{\beta}_{F V I X}$ & -0.620 & -1.509 & -1.869 & -1.249 \\
t-stat & -3.64 & -5.85 & -2.92 & -2.20 & t-stat & -2.73 & -3.40 & -5.48 & -4.19 \\
\hline \hline
\end{tabular}




\section{Table 8. Alternative Measures of Aggregate Volatility Risk}

The table presents the alphas (Panel A) and aggregate volatility risk betas (Panels B and $\mathrm{C}$ ) from the following six models:

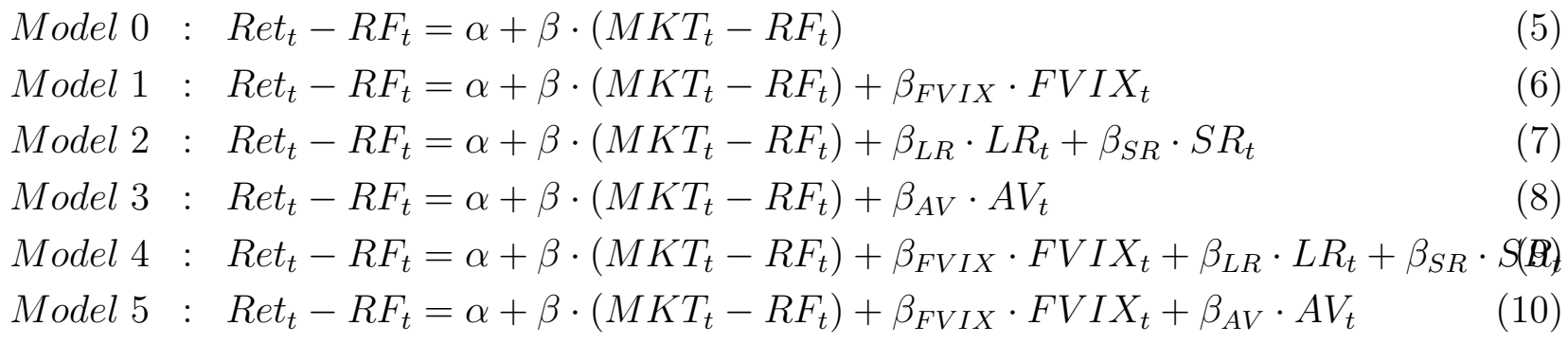

The volatility risk factors are FVIX (the factor-mimicking portfolio tracking the changes in VIX), the short-run (SR) and long-run (LR) market volatility components from the CGARCH model in Adrian and Rosenberg (2008), and the average volatility factor (AV) from Chen and Petkova (2012). Panel B uses innovations to LR, SR, and AV, Panel C uses factor-mimicking portfolios that track the innovations (the base assets are quintile portfolios sorted on the sensitivity to the innovations in the past 36 months). Detailed descriptions of the volatility risk factors are in Data Appendix.

The test assets on the left-hand side of the equations above are the long-minus-short portfolios that firms with low and short firms with high values of maximum daily return in the past month (Max), expected idiosyncratic skewness (ESkew), minimum daily return (times -1) in the past month (Min), idiosyncratic volatility (IVol), and analyst forecast dispersion (Disp). The $t$-statistics (in italics) use the Newey-West (1987) correction for heteroskedasticity and autocorrelation. The sample period is from January 1986 to December 2010. The sample used to form the low-minus-high portfolios excludes the stocks with per share price less than $\$ 5$ on the portfolio formation date.

Panel A. Alphas from Competing Models

\begin{tabular}{lcccccc}
\hline \hline & $\mathbf{0}$ & $\mathbf{1}$ & $\mathbf{2}$ & $\mathbf{3}$ & $\mathbf{4}$ & $\mathbf{5}$ \\
\hline \hline Max & 0.600 & -0.112 & 0.355 & 0.572 & 0.134 & -0.118 \\
t-stat & 2.30 & -0.47 & 2.09 & 2.08 & 0.74 & -0.48 \\
\hline ESkew & 0.539 & -0.082 & 0.345 & 0.504 & 0.110 & -0.089 \\
t-stat & 2.21 & -0.29 & 1.49 & 2.00 & 0.44 & -0.32 \\
\hline Min & 0.572 & -0.140 & 0.345 & 0.550 & 0.064 & -0.144 \\
t-stat & 2.26 & -0.62 & 1.85 & 2.03 & 0.35 & -0.62 \\
\hline IVol & 0.822 & -0.073 & 0.495 & 0.801 & 0.224 & -0.075 \\
t-stat & 2.80 & -0.27 & 2.48 & 2.63 & 1.16 & -0.27 \\
\hline Disp & 0.539 & -0.137 & 0.307 & 0.525 & 0.078 & -0.136 \\
t-stat & 2.33 & -0.63 & 1.73 & 2.16 & 0.44 & -0.62 \\
\hline \hline
\end{tabular}


Panel B. Volatility Risk Betas: Non-Traded Alternative Factors

\begin{tabular}{lccccccccc}
\hline \hline & $\mathbf{1}$ & \multicolumn{2}{c}{$\mathbf{2}$} & \multicolumn{3}{c}{$\mathbf{4}$} & \multicolumn{2}{c}{$\mathbf{5}$} \\
& $\boldsymbol{\beta}_{F V I X}$ & $\boldsymbol{\beta}_{L R}$ & $\boldsymbol{\beta}_{S R}$ & $\boldsymbol{\beta}_{A V}$ & $\boldsymbol{\beta}_{F V I X}$ & $\boldsymbol{\beta}_{L R}$ & $\boldsymbol{\beta}_{S R}$ & $\boldsymbol{\beta}_{F V I X}$ & $\boldsymbol{\beta}_{A V}$ \\
\hline Max & -1.544 & -0.115 & -1.829 & -9.289 & -1.533 & -0.165 & -0.770 & -1.645 & -16.790 \\
t-stat & -3.38 & -1.59 & -3.10 & -1.81 & -3.31 & -2.25 & -1.22 & -3.60 & -4.46 \\
\hline ESkew & -1.280 & 0.132 & -2.125 & 16.653 & -1.180 & 0.078 & -1.150 & -1.232 & 8.097 \\
t-stat & -3.54 & 2.24 & -4.30 & 2.95 & -3.09 & 1.27 & -1.94 & -3.44 & 1.48 \\
\hline Min & -1.546 & -0.061 & -1.734 & -7.065 & -1.527 & -0.110 & -0.679 & -1.629 & -14.494 \\
t-stat & -4.76 & -0.95 & -2.92 & -1.73 & -4.67 & -1.96 & -1.16 & -5.17 & -4.52 \\
\hline IVol & -1.864 & 0.041 & -2.188 & -0.462 & -1.809 & -0.022 & -0.931 & -1.916 & -9.199 \\
t-stat & -4.24 & 0.48 & -2.95 & -0.07 & -4.04 & -0.28 & -1.24 & -4.39 & -1.99 \\
\hline Disp & -1.471 & 0.006 & -1.905 & 0.925 & -1.420 & -0.041 & -0.931 & -1.517 & -5.996 \\
t-stat & -6.05 & 0.09 & -3.05 & 0.22 & -5.74 & -0.84 & -1.73 & -6.40 & -1.44 \\
\hline \hline
\end{tabular}

Panel C. Volatility Risk Betas: Traded Alternative Factors

\begin{tabular}{lccccccccc}
\hline \hline & $\mathbf{1}$ & \multicolumn{2}{c}{$\mathbf{2}$} & $\mathbf{3}$ & \multicolumn{3}{c}{$\boldsymbol{4}$} \\
& $\boldsymbol{\beta}_{F V I X}$ & $\boldsymbol{\beta}_{L R}$ & $\boldsymbol{\beta}_{S R}$ & $\boldsymbol{\beta}_{A V}$ & $\boldsymbol{\beta}_{F V I X}$ & $\boldsymbol{\beta}_{L R}$ & $\boldsymbol{\beta}_{S R}$ & $\boldsymbol{\beta}_{F V I X}$ & $\boldsymbol{\beta}_{A V}$ \\
\hline \hline Max & -1.544 & 0.023 & -0.389 & -0.824 & -0.586 & 0.022 & -0.310 & -1.533 & -0.338 \\
t-stat & -3.38 & 4.18 & -10.62 & -0.61 & -1.61 & 4.51 & -5.65 & -3.43 & -0.40 \\
\hline ESkew & -1.280 & 0.017 & -0.308 & -1.425 & -0.584 & 0.016 & -0.228 & -1.244 & -1.030 \\
t-stat & -3.54 & 3.09 & -6.41 & -1.18 & -2.58 & 3.26 & -4.27 & -4.00 & -1.44 \\
\hline Min & -1.546 & 0.017 & -0.363 & -0.675 & -0.743 & 0.017 & -0.263 & -1.539 & -0.187 \\
t-stat & -4.76 & 3.06 & -9.95 & -0.50 & -3.25 & 3.18 & -5.50 & -4.72 & -0.20 \\
\hline IVol & -1.864 & 0.022 & -0.478 & -0.677 & -0.701 & 0.022 & -0.383 & -1.861 & -0.104 \\
t-stat & -4.24 & 4.23 & -13.51 & -0.45 & -2.31 & 4.41 & -6.89 & -4.28 & -0.12 \\
\hline Disp & -1.471 & 0.013 & -0.372 & -0.430 & -0.614 & 0.013 & -0.289 & -1.472 & 0.037 \\
t-stat & -6.05 & 2.81 & -13.90 & -0.42 & -3.58 & 3.03 & -8.96 & -6.00 & 0.06 \\
\hline \hline
\end{tabular}

